\title{
Different Levels of Care for Follow-up of Adults with Congenital Heart Disease
}

\section{A Cost Analysis Scrutinizing the Impact on Medical Costs, Hospitalizations, and Emergency Department Visits}

Ruben Willems ${ }^{1 *}$, Fouke Ombelet ${ }^{2}$, Eva Goossens ${ }^{2,3,4}$, Katya De Groote ${ }^{5}$, Werner Budts ${ }^{6,7}$, Stéphane Moniotte ${ }^{8}$, Michèle de Hosson ${ }^{9}$, Liesbet Van Bulck ${ }^{2,4}$, Arianne Marelli ${ }^{10}$, Philip Moons $^{2,11,12}$, Julie De Backer ${ }^{4,9 t}$, Lieven Annemans ${ }^{1 t}$, on behalf of the BELCODAC consortium

${ }^{1}$ Department of Public Health and Primary Care, Ghent University, Ghent, Belgium

${ }^{2} \mathrm{KU}$ Leuven Department of Public Health and Primary Care, Academic Center for Nursing and Midwifery, KU Leuven - University of Leuven, Leuven, Belgium

${ }^{3}$ Faculty of Medicine and Health Sciences, Centre for Research and Innovation in Care, Division of Nursing and Midwifery, University of Antwerp, Antwerp, Belgium

${ }^{4}$ Research Foundation Flanders (FWO), Brussels, Belgium

${ }^{5}$ Department of Pediatric Cardiology, University Hospital Ghent, Ghent, Belgium

${ }^{6} \mathrm{KU}$ Leuven Department of Cardiovascular Sciences, KU Leuven - University of Leuven, Leuven, Belgium

${ }^{7}$ Division of Congenital and Structural Cardiology, University Hospitals Leuven, Leuven, Belgium

${ }^{8}$ Pediatric and Congenital Cardiology Division, St-Luc University Hospital, Brussels, Belgium

${ }^{9}$ Department of Adult Congenital Cardiology, Ghent University Hospital, Belgium

${ }^{10}$ McGill Adult Unit for Congenital Heart Disease Excellence (MAUDE Unit), McGill University Health Center, Montreal, Quebec, Canada

${ }^{11}$ Institute of Health and Care Sciences, University of Gothenburg, Gothenburg, Sweden

${ }^{12}$ Department of Pediatrics and Child Health, University of Cape Town, Cape Town, South Africa 
*Address for correspondence:

Ruben Willems, PhD

Corneel Heymanslaan 10, Entrance 42, Floor 4, 9000 Ghent, Belgium

Tel: +3293328332; fax: +3293324994; E-mail: Ruben.Willems@ugent.be

Orcid: 0000-0001-8732-9455

'Shared last author.

\section{DECLARATIONS}

\section{Acknowledgements}

The authors thank all employees working at StatBel and the InterMutualistic Agency for their contribution to the data collection and their valuable input on the selection of the variables.

\section{Funding}

This work was supported by Research Foundation Flanders [G097516N to PM and 12E9816N to EG], the Fondation Nationale de Reserche en Cardiologie Pédiatrique, and the King Baudouin Foundation (Fund Joseph Oscar Waldmann-Berteau \& Fund Walckiers Van Dessel). JDB is supported as senior clinical researcher, EG as postdoctoral researcher, and LVB as predoctoral researcher by the Research Foundation Flanders.

\section{Competing interests}

None to declare.

\section{Availability of data and material}

Not available.

\section{Code availability}

Not applicable.

\section{Ethics approval}

The study was approved by the privacy commission (SCSZG/17/184) and the ethical committees of the participating hospitals (S59858, B670201731994, 2017/26JUI/332). 


\section{Contribution}

RW: conceptualization, methodology, formal analysis, data curation, writing - original draft, visualization, project administration; FO: conceptualization, methodology, data curation, writing - review \& editing, project administration; EG: conceptualization, methodology, writing - review \& editing; KDG: resources, writing - review \& editing; WB: funding acquisition, resources, writing - review \& editing; SM: funding acquisition, resources, writing - review \& editing; MDH: resources, writing - review \& editing; LVB: project administration, writing review \& editing; AM: funding acquisition, writing - review \& editing; PM: writing - review \& editing, funding acquisition; JDB: supervision, resources, writing - review \& editing, funding acquisition; LA: supervision, writing - review \& editing, funding acquisition. 
1 Different Levels of Care for Follow-up of Adults with Congenital Heart

2 Disease

3 A Cost Analysis Scrutinizing the Impact on Medical Costs, Hospitalizations, and Emergency Department Visits

\section{ABSTRACT}

Aim

To scrutinize the economic impact of different care levels, such as shared care, in the followup of adult congenital heart disease (ACHD) patients.

Methods

The BELgian COngenital heart disease Database combining Administrative and Clinical data (BELCODAC) was analyzed. Patients $(\mathrm{N}=6,579)$ were categorized into five care levels based on their cardiac follow-up pattern between 2006 and 2010. Medical costs, hospitalizations, and emergency department visits were measured between 2011 and 2015.

Results

In patients with moderate lesions, highly specialized cardiac care (HSC; exclusive follow-up by ACHD specialists) and shared care with predominantly specialized cardiac care (SC+) were associated with significantly lower medical costs and resource use compared to shared care with predominantly general cardiac care (SC-) and general cardiac care (GCC). In the patient population with mild lesions, HSC was associated with better economic outcomes than SCand GCC, but SC+ was not. HSC was associated with fewer hospitalizations (-33\%) and less pharmaceutical costs (-46.3\%) compared to SC+. Patients with mild and moderate lesions in the no cardiac care (NCC) group had better economic outcomes than those in the GCC and SCgroups, but post-hoc analysis revealed that they had a different patient profile than patients under cardiac care.

Conclusion

More specialized care levels are associated with better economic outcomes in patients with mild or moderate lesions in cardiac follow-up. Shared care with strong involvement of ACHD specialists might be a management option to consider. Characteristics of patients without cardiac follow-up but good medium-term economic prospects should be further scrutinized. 


\section{Keywords}

Healthcare economics; congenital heart disease; health services; follow-up care

\section{JEL classification codes}

D610, 1110

\section{INTRODUCTION}

The adult population with congenital heart disease (CHD) expanded[1,2] over the past decades and the care needs per patient increased. Together this could impose a pressing burden on available medical and financial resources[3,4]. Adult congenital heart disease (ACHD) specialized centers have been established to deliver appropriate care to these patients with lifelong care needs[5,6], but the existing ACHD specialized centers may eventually face saturation as the patient population is expected to keep on growing and ageing. To ensure and to improve the quality and sustainability of the long-term care for adults with CHD, international expert-opinion based recommendations advocated a three-level care model[79]. Adults with CHD should be seen at least once at an ACHD specialized center to determine the most appropriate follow-up level based on anatomy and physiological stage: (i) exclusive care at an ACHD specialized center, (ii) shared care between the specialized center and general cardiac care providers, and (iii) non-specialist cardiac care provided by general cardiologists with direct access to specialized care if needed.

The limited research available on the topic of the dominant level of care demonstrated better patient outcomes following specialized cardiac care compared to general cardiac care, particularly in patients with severe lesions[10,11]. Mylotte et al. showed a significant increase of patients referred to ACHD centers after national consensus guideline publication, resulting in a significant decrease in mortality a few years later. The analysis of the impact of shared care on mortality was hampered by the small number of patients categorized in this care group[10]. Cordina et al. demonstrated that general cardiologists deviated significantly more from clinical guidelines than ACHD specialists. Patients followed by general cardiologists subsequently suffered more from negative outcomes (e.g., death, permanent disability) or inadequate management (e.g., not recommending a necessary intervention)[11]. The impact of shared care is ought to be investigated. 
The aim of this study was to explore the association between different care levels and future economic outcomes such as medical costs and resource use (i.e., emergency department (ED) visits and hospitalizations). Although a three-level care model was advocated in the above mentioned guidelines, we explored five different care levels. Shared care was dichotomized as the grade of collaboration between general cardiologists and ACHD specialists can vary widely. Furthermore, we aimed to explore the association between no cardiac care and economic outcomes.

\section{METHODS}

\section{Database and patient population}

The Belgian Congenital Heart Disease Database combining Administrative and Clinical data (BELCODAC) has been used to conduct this retrospective study. A detailed description of the linking process and the included variables have been described in a separate paper[12]. Briefly, the BELCODAC comprises healthcare utilization data from ten consecutive years (i.e., 2006-2015), and clinical data from the same period and before (e.g., information about interventions). Particularly, ten databases from five organizations were merged:

- The Intermutualistic Agency (IMA) is the umbrella organization of the seven Belgian sickness funds. The IMA delivered three population-level databases: (i) the population database (socio-demographic information), (ii) the pharmanet database (medication supply information), and (iii) the medical claims database (medical care information).

- Statistics Belgium collects, processes and distributes data about the Belgian society, and they delivered four population-level databases: (i) the death certificate database, (ii) the socio-demographic database, (iii) the socio-economic database, and (iv) the IPCAL database (income information).

- $\quad$ Ghent University Hospital, University Hospitals Leuven and St-Luc University Hospitals each provided part of the study population and delivered clinical information.

In 2004, Belgian law designated four specialized hospitals to provide the full spectrum of CHD care including congenital cardiac surgery and ACHD care[13], and outpatient clinics have been established in affiliated satellite centers as well. The BELCODAC was populated with all CHD patients from the two specialized Flemish hospitals (Ghent University Hospital and University Hospitals Leuven). Additionally, patients with severe lesions of St-Luc University Hospital 
(Brussels Capital region) were included in the BELCODAC to get a reasonable number of patients in all lesion complexity groups[14]. Included patients attended the specialized clinic at least once throughout their life. This was not necessarily between 2006 and 2015 as the visit could have taken place earlier in life. Patients who have never visited a specialized center were not included in the database. For the present study's research aim, a closed cohort was applied with the inclusion of all patients alive and 18 years or older on 01/01/2006, and still alive on $31 / 12 / 2010$.

\section{Statistical framework}

Patients were categorized based on their primary diagnosis into lesion complexity groups (i.e., mild, moderate, severe) as defined by Task Force 1 of the $32^{\text {nd }}$ Bethesda Conference[15], but the presence of a secondary diagnosis could have resulted in getting categorized into a more severe lesion complexity group. Patients per lesion complexity were then categorized in five care levels based on the frequency and proportion of their outpatient cardiology visits with general cardiologists and ACHD specialists between 2006 and 2010. Five care levels were defined: (i) highly specialized cardiac care (HSC), (ii) shared care with predominantly specialized cardiac care (SC+), (iii) shared care with predominantly general cardiac care (SC-), (iv) exclusive general cardiac care (GCC), and (v) no cardiac care (NCC) (see Table 1). Visits with general cardiologists in the ED context were not taken into account while determining the care level.

Since there are multiple care levels for each complexity group, we applied the Propensity Score Subclassification method for multiple treatment options to evaluate the impact of care level on outcomes. This method has been found useful in non-randomized study designs to approach randomization. Particularly, this work followed the statistical methodology as described by Zanutto et al.[16]. A detailed description of the statistical procedures (e.g., how we dealt with covariate imbalance) can be found in supplement S1.

To start, for patients with mild, moderate and severe lesions separately, Ordinal Logit Models were used to calculate patient-specific propensity scores. A propensity score can be defined as the chance of receiving a given level of care based on a set of baseline characteristics. In this study, 12 demographic, socio-economic and clinical covariates were selected (i.e., self- 
119 employment, marital status, household type, household income, eligibility for increased 120 reimbursement, an indicator of chronic illness, number of available informal caregivers, 121 number of interventions, age, sex, syndrome, and primary CHD diagnosis).

122 Then, a region of overlap had to be determined based on the propensity scores. The 123 boundaries of the region of overlap can be defined as the highest minimum score and the 124 lowest maximum score across the five care levels. Patients with a propensity score outside the region of overlap were excluded from further analysis. Summary statistics of the included and excluded patients were checked as the obtained results could only be applied on the subpopulation represented by the region of overlap. Patients included for further analysis were classified in ten equally sized deciles based on their propensity score (five equally sized quintiles for patients with severe lesions because of the smaller sample size).

Outcomes were estimated using generalized linear models (gamma distribution, log-link function) with the care level as independent variable. The impact of care level was adjusted for the propensity score quintile/decile and, if covariate imbalance could not be avoided, for the covariates with remaining imbalance.

134 The impact of care level between 2006 and 2010 was measured on future economic outcomes 135 between 2011 and 2015, taking a payer's perspective. The primary outcome was total medical 136 costs (cardiac and non-cardiac aggregated), which consisted of hospitalization, outpatient 137 (e.g. honoraria, technical medical provisions), and pharmaceutical costs. All costs between 1382011 and 2015 were inflated to the same base year applying the Consumer Price Index[17]. 139 Two types of resource use were considered as secondary outcomes (i.e., ED visits and all-type 140 hospitalizations). All outcomes were recalculated to a measurement per patient year to 141 account for mortality between 2011 and 2015. Results are presented as the percentage 142 difference between care levels. P-values of $\leq .05$ were considered significant with two-sided 143 tests. We did not adjust for multiple testing: this study should be seen as exploratory as there 144 is currently little literature available on the topic.

\section{Sensitivity analysis: exclusion of deceased patients}

146 Although the results were calculated per patient year, we should acknowledge that the 147 economic outcomes of this study remained subject to the competing risk of death. For 148 example, hospital admissions costs are known to be higher when a patient dies during 
admission[18]. Therefore, the robustness of our results was checked by redoing our analyses, but with the exclusion of patients who died during the study period.

Analyses were performed with SAS Enterprise Guide V.7.1 (SAS Institute Inc., Cary, NC, USA).

\section{RESULTS}

\section{Demographics}

The initial sample consisted of 6,959 patients of which 111, 162 and 107 patients with respectively mild, moderate and severe lesions were excluded because their propensity score was outside the region of overlap. Therefore, the final sample size yielded 3,633 (97.0\% of the initial sample size), 2,727 (94.4\%), and 219 (67.2\%) patients with mild, moderate, and severe lesions respectively, totaling 6,579 patients. Atrial septal defect (ASD) type 2 and ventricular septal defect (VSD) were the most prevalent primary diagnoses in patients with mild lesions. A large majority of patients with mild lesions (80\%) had no contact with an ACHD specialist between 2006 and 2010 and were therefore categorized in either care level NCC (42.2\%) or GCC (37.8\%). Pulmonary valve abnormality, coarctation of the aorta, and tetralogy of Fallot were the most prevalent primary diagnoses in patients with moderate lesions. Nearly half of these patients were classified in care levels representing shared care (care level SC- or SC+) or highly specialized care (care level HSC). Transposition of the great arteries, univentricular physiology, and double outlet right ventricle were the most prevalent primary diagnoses in patients with severe lesions. A large majority of patients in this group (82.2\%) were classified in care levels representing shared care or HSC (Table 2).

- Please insert Table 2 around here -

Figure 1 shows the total cost differences between the five care levels for patients with mild and moderate lesions. Figure 2 shows the ED visits and hospitalization rate differences. Full results can be found in Supplement S1. Results for patients with severe lesions were hampered by a small sample size (see also the discussion section).

\section{Patients with moderate lesions}

\section{Medical costs}

HSC and SC+ were associated with significantly less total costs compared to SC- and GCC. The HSC and SC+ groups incurred significantly less hospitalization costs than the SC- $-41.8 \%$ and $42.2 \%$ respectively), and the GCC (-34.8\% and $-35.3 \%$ respectively) groups. Pharmaceutical 
costs were significantly lower in the HSC and SC+ groups compared to the SC- $(-44.6 \%$ and $36.3 \%$ respectively) and GCC (-27.5\% and non-significant respectively) groups. The HSC group also incurred significantly less outpatient costs than the SC- (-13.9\%) and GCC (-14.8\%) groups.

182 A trend was observed on the outpatient cost difference between on the one hand the SC+ group and on the other hand the SC- and GCC groups.

184 The NCC group was associated with significantly lower total costs compared to the SC- and 185 GCC groups, caused by higher hospitalization, outpatient, and pharmaceutical costs in the SC186 group $(+43.8 \%,+26.3 \%$, and $+99.1 \%$ respectively), and higher outpatient and pharmaceutical costs in the GCC group ( $+27.6 \%$ and $+52.0 \%$ respectively).

- Please insert Figure 1 around here -

\section{ED visits and hospitalizations}

Patients in the HSC and SC+ groups were significantly less hospitalized than those in the SC- ($38.5 \%$ and $-24.4 \%$ respectively), and the GCC groups (-34.3\% and non-significant respectively). The number of ED visits did not differ significantly.

Hospitalizations and ED visits were significantly more frequent in the SC- $(+37.7 \%$ and $+33.2 \%$ respectively) and GCC groups (+28.9\% and $+32.2 \%$ respectively) than in the NCC group.

\section{- Please insert Figure 2 around here -}

\section{Patients with mild lesions}

\section{Medical costs}

The HSC group incurred significantly less total costs up to 5 years later than the GCC group, and a trend towards less medical costs was observed compared to the SC-group. Total costs between the SC+ group and SC-, and GCC groups did not differ. Specifically, the HSC group was associated with significantly lower hospitalization costs than the GCC group $(-48.2 \%)$ and a trend towards lower hospitalization costs than the SC- group (-33.3\%). Pharmaceutical costs were significantly lower for the HSC group compared to the SC+ $(-46.3 \%), \mathrm{SC}-(-35.1 \%)$ and GCC groups (-26.1\%). The HSC and SC- groups were also associated with less outpatient costs compared to the GCC group (-14.1\% and $-15.6 \%$ respectively).

The NCC group was associated with less total costs than the GCC group and a trend towards less total costs compared to the SC-group, as a result of higher pharmaceutical costs in the 
SC- (+83.3\%) and GCC groups (+60.9\%), and more hospitalization (+21.5\%) and outpatient costs (+23.5\%) in the GCC group.

\section{ED visits and hospitalizations}

211 Patients in the HSC group were significantly less hospitalized than those in the SC- group ($21230.8 \%)$, and the GCC group (-35.2\%), and there was a trend towards fewer hospitalizations 213 compared to the SC+ group $(-33.0 \%, \mathrm{p}$-value=0.07). The HSC group was also associated with 214 significantly fewer ED visits than the SC- group (-29.3\%) and a trend towards fewer ED visits 215 than the GCC group $(-24.7 \%, p$-value=0.052). No other estimates yielded significant 216 differences.

217 Patients in the GCC group were significantly more hospitalized (+22.0\%) than those in the NCC 218 group, and ED visits occurred significantly more frequently in the SC- (+32.3\%) and GCC groups $219(+24.3 \%)$ than in the NCC group.

\section{Differences between patients with and without cardiac follow-up}

221 Although the statistical analyses tried to account for the care levels so that patients in different 222 levels had similar baseline characteristics, some imbalance remained (Supplement S1). 223 Indeed, post-hoc analysis showed how patients without cardiac follow-up differed from all 224 other patients: patients with mild lesions not under cardiac follow-up were younger, had 225 fewer comorbid syndromes, less chronic illness, and more often had a ventricular septal defect 226 as a primary diagnosis. Patients with moderate lesions not under cardiac follow-up had undergone fewer interventions, had less chronic illness, more often had a pulmonary valve or aortic abnormality as a primary diagnosis, and less often a tetralogy of Fallot or coarctation

229 of the aorta.

\section{Sensitivity analysis}

231 Full results of the sensitivity analysis can be found in Supplement S2. The exclusion of patients 232 who died during the study period led to a few statistically significant results becoming 233 insignificant or just a trend towards significance (and vice versa as well). However, this did not 234 lead to substantial differences or conclusion-changing results, which reinforced the initial 235 results. 
237 This multi-center study used a retrospective database research design linking administrative 238 and clinical data to determine the impact of care levels on medical costs and resource use in 239 the medium term. Patients with mild or moderate lesions who received cardiac care appeared 240 to incur less medical costs in the medium term (i.e., up to 5 years later) when being followed 241 at more specialized cardiac care levels.

242 Our economic findings are in line with the clinical results of Cordina et al.[11] and Mylotte et 243 al.[10] who found that, regardless of lesion's complexity grade, patients with CHD benefit from 244 specialized cardiac care over general cardiac care. Our study showed that both patients with mild and moderate lesions under highly specialized cardiac care incurred less hospitalization, outpatient and pharmaceutical costs in the medium term compared to patients under general

247 cardiac care. It is therefore important to keep working on referral patterns from general to specialized cardiac care by improving communication, feedback, and knowledge distribution between care levels[19].

A particular interest of this paper was to investigate the potential role of shared care as suggested in existing clinical guidelines[7-9]. Shared care in this paper was dichotomized in shared care with a high share of specialized cardiac care (SC+) and a low share of specialized cardiac care (SC-). In patients with moderate lesions, the economic outcome in SC+ and HSC did not differ and those two levels of care were associated with fewer hospitalizations and less medical costs compared to SC-. Similarly, in patients with mild lesions, SC- was associated with higher costs, more hospitalizations and ED visits compared to highly specialized care, but not to SC+. Moreover, SC+ was associated with higher pharmaceutical costs and a trend towards more hospitalizations compared to highly specialized cardiac care. On first sight, it may seem contra-intuitive to find statistically significant differences between the SC+ group and the highly specialized cardiac care group in patients with mild lesions while there were no such differences found in patients with moderate lesions. One would expect it to be the other way around. One explanation could be that patients with mild lesions in this study were considerably older on average and previous research demonstrated increasing medical needs 264 with higher age[4,20,21]. For example, CHD patients $\geq 40$ years had an $87 \%$ higher risk of being hospitalized compared to CHD patients under 30[4]. Following this reasoning, exclusive 
may be sufficient for young adult patients with CHD if the ACHD specialist is strongly involved in the follow-up process. The specificity of $\mathrm{CHD}$ in conjunction with acquired heart disease[20,22] and non-cardiac comorbidities[23,24,22], and the commonly faced need for (re)operation[25] with advancing age may require exclusive specialized cardiac care.

271 The economic outcomes of patients who did not receive any cardiac care between 2006 and

2722010 were not in line with the expected (and otherwise also observed) relation that higher 273 care levels result in less medical costs and less resource use. Patients without cardiac follow274 up had rather good economic prospects, suggesting that things do not go wrong in the 275 medium term. It may be that particular patient groups would not immediately benefit from 276 specialized cardiac care. Our post-hoc analyses provide important information on which 277 patients are less prone to be under cardiac follow-up. These results should be seen as an 278 important first step towards determining which patients do not necessarily benefit from 279 cardiac follow-up. Such research is of particular importance as human and financial resources are limited, and overuse should be avoided so that more resources become available to properly care for those patients in need. These results thus support the recommendation that every patient should be seen at a specialized center at least once[7-9] to determine the appropriate level of care, which may be no cardiac care. However, future research on the specific profile of these patients is warranted as this study cannot make inferences on longterm prospects. It is possible that patients without cardiac follow-up have a subclinical cardiac problem that would already have been noticed and treated to prevent worse outcomes on the long-term if they had had regular cardiac follow-up[26]. The question remains if an infrequent but periodical cardiac check-up would still be relevant for all patients because safe might be better than sorry.

\section{Limitations}

291 Several limitations inherent to the analyses were identified, next to known limitations of 292 retrospective database research such as the fact that data were not primarily collected to answer the research question[27].

294 First, for methodological reasons, analyses were restricted to the propensity score region of overlap, which is methodologically sound, but hampers the generalization to the entire ACHD population. Patient population characteristics of the excluded patients deviating from the

297 included patient population can be found in Supplement S1. 
Second, the small number of patients with severe lesions in some care levels hampered the analysis. Robust inferences could not be drawn from this subpopulation. Moreover, a similar remark could be made concerning the results for patients with mild and moderate lesions. Although the sample sizes were quite large, there was a skewed distribution of patients across the five care levels. Together with strong within-group variance, which is typical for economic data such as cost data, statistically significant results could not always be obtained for substantial numerical differences between care levels.

Third, the categorization of patients led inevitably to a loss of information. The definition we applied for categorization patients into care levels has its limitations because, for example, a patient with only one outpatient contact with an ACHD specialist was categorized in the HSC group while at the same time the recommended follow-up frequency might be higher. Can the patient then be considered as someone in the highest care level? Moreover, the BELCODAC does not allow to study the quality of the collaboration between general cardiologists and ACHD specialists, which may have an important impact on the quality of the shared care, and thus on patient outcomes.

313 Fourth, we did not adjust for multiple testing because this study should be interpreted as an exploratory study as available literature on the topic is rare. Type 1 errors are less harmful than type 2 errors at this stage. Future confirmatory studies with enough statistical power should adjust for multiple testing as found appropriate.

317 Last but not least, the analysis of the impact of care level on medical costs and resource use in patients with severe lesions was hampered by the small sample size resulting in wide confidence intervals and a high probability of type 2 errors. Results were therefore not explored in detail. Given previous findings which compared specialized with general cardiac care in patients with severe lesions[10,11], we can expect that with a larger sample size, we would have obtained results in favor of specialized care levels in line with the results that were obtained in patients with mild and moderate lesions, but even more pronounced. However, we cannot make inferences about the potential of shared care with a strong component of specialized care (i.e., care level SC+) next to highly specialized care for patients with severe lesions. 
328 This study indicates that patients with mild and moderate lesions followed exclusively at ACHD specialized centers incurred less medical costs than patients followed by general cardiologists. Shared care with a strong involvement of ACHD specialists in follow-up care might result in lower future medical costs as well, but future research should scrutinize the impact of moderating variables such as patients' age. Finally, research to scrutinize characteristics of patients without cardiac follow-up, but seemingly good economic prospects, is warranted.

\section{REFERENCES}

335

336

337

338

339

340

341

342

343

344

345

346

347

348

349

350

351

352

353

354

355

356

357

358

359

360

361

362

363

364

365

366

367

368

369

1. Marelli, A.J., Ionescu-Ittu, R., Mackie, A.S., Guo, L., Dendukuri, N., Kaouache, M.: Lifetime prevalence of congenital heart disease in the general population from 2000 to 2010. Circulation 130(9), 749-756 (2014). doi:10.1161/circulationaha.113.008396

2. Bouma, B.J., Mulder, B.J.: Changing Landscape of Congenital Heart Disease. Circulation research 120(6), 908-922 (2017). doi:10.1161/circresaha.116.309302

3. Willems, R., Werbrouck A, De Backer J, Annemans L: Real-World Healthcare Utilization in Adult Congenital Heart Disease. Cardiology in the young 29(5), 553-563 (2019).

4. Willems, R., Ombelet, F., Goossens, E., De Groote, K., Budts, W., Moniotte, S., de Hosson, M., Van Bulck, L., Marelli, A., Moons, P., De Backer, J., Annemans, L.: Long-term Healthcare Utilization, Medical Cost, and Societal Cost in Adult Congenital Heart Disease. Congenital heart disease 15(6), 399-429 (2020). doi:10.32604/CHD.2020.011709

5. Moons, P., Meijboom, F.J., Baumgartner, H., Trindade, P.T., Huyghe, E., Kaemmerer, H.: Structure and activities of adult congenital heart disease programmes in Europe. European heart journal 31(11), 1305-1310 (2010). doi:10.1093/eurheartj/ehp551

6. Thomet, C., Moons, P., Budts, W., De Backer, J., Chessa, M., Diller, G., Eicken, A., Gabriel, H., Gallego, P., Giamberti, A., Roos-Hesselink, J., Swan, L., Webb, G., Schwerzmann, M., Disease, E.S.C.W.G.o.G.-U.C.H.: Staffing, activities, and infrastructure in 96 specialised adult congenital heart disease clinics in Europe. International journal of cardiology 292, 100-105 (2019). doi:10.1016/j.ijcard.2019.04.077

7. Baumgartner, H., Budts, W., Chessa, M., Deanfield, J., Eicken, A., Holm, J., Iserin, L., Meijboom, F., Stein, J., Szatmari, A., Trindade, P.T., Walker, F.: Recommendations for organization of care for adults with congenital heart disease and for training in the subspecialty of 'Grown-up Congenital Heart Disease' in Europe: a position paper of the Working Group on Grown-up Congenital Heart Disease of the European Society of Cardiology. European heart journal 35(11), 686-690 (2014). doi:10.1093/eurheartj/eht572

8. Warnes, C.A., Williams, R.G., Bashore, T.M., Child, J.S., Connolly, H.M., Dearani, J.A., Del Nido, P., Fasules, J.W., Graham, T.P., Jr., Hijazi, Z.M., Hunt, S.A., King, M.E., Landzberg, M.J., Miner, P.D., Radford, M.J., Walsh, E.P., Webb, G.D.: ACC/AHA 2008 Guidelines for the Management of Adults with Congenital Heart Disease: Executive Summary: a report of the American College of Cardiology/American Heart Association Task Force on Practice Guidelines (writing committee to develop guidelines for the management of adults with congenital heart disease). Circulation 118(23), 2395-2451 (2008). doi:10.1161/circulationaha.108.190811 
9. Stout, K.K., Daniels, C.J., Aboulhosn, J.A., Bozkurt, B., Broberg, C.S., Colman, J.M., Crumb, S.R., Dearani, J.A., Fuller, S., Gurvitz, M., Khairy, P., Landzberg, M.J., Saidi, A., Valente, A.M., Van Hare, G.F.: 2018 AHA/ACC Guideline for the Management of Adults With Congenital Heart Disease: Executive Summary: A Report of the American College of Cardiology/American Heart Association Task Force on Clinical Practice Guidelines. Journal of the American College of Cardiology 73(12), 1494-1563 (2019). doi:10.1016/j.jacc.2018.08.1028

10. Mylotte, D., Pilote, L., Ionescu-Ittu, R., Abrahamowicz, M., Khairy, P., Therrien, J., Mackie, A.S., Marelli, A.: Specialized adult congenital heart disease care: the impact of policy on mortality. Circulation 129(18), 1804-1812 (2014). doi:10.1161/circulationaha.113.005817

11. Cordina, R., Nasir Ahmad, S., Kotchetkova, I., Eveborn, G., Pressley, L., Ayer, J., Chard, R., Tanous, D., Robinson, P., Kilian, J., Deanfield, J.E., Celermajer, D.S.: Management errors in adults with congenital heart disease: prevalence, sources, and consequences. European heart journal 39(12), 982-989 (2018). doi:10.1093/eurheartj/ehx685

12. Ombelet, F., Goossens, E., Willems, R., Annemans, L., Budts, W., De Backer, J., De Groote, K., Moniotte, S., Van Bulck, L., Marelli, A., Moons, P.: Creating the BELgian COngenital heart disease Database combining Administrative and Clinical data (BELCODAC): rationale, design and methodology. International journal of cardiology 316, 72-78 (2020). doi:https://doi.org/10.1016/i.ijcard.2020.05.059

13. Koninklijk Besluit houdende vaststelling van de normen waaraan de zorgprogramma's

"cardiale pathologie" moeten voldoen om erkend te worden [Royal Resolution on the norms care programs 'cardiac pathology' should meet in order to be certified]. In.

Belgian Government, (2004)

14. Clabaugh, G., Ward, M.M.: Cost-of-illness studies in the United States: a systematic review of methodologies used for direct cost. Value in health : the journal of the International Society for Pharmacoeconomics and Outcomes Research 11(1), 13-21 (2008). doi:10.1111/j.1524-4733.2007.00210.x

15. Warnes, C.A., Liberthson, R., Danielson, G.K., Dore, A., Harris, L., Hoffman, J.I., Somerville, J., Williams, R.G., Webb, G.D.: Task force 1: the changing profile of congenital heart disease in adult life. Journal of the American College of Cardiology 37(5), 1170-1175 (2001).

16. Zanutto, E., Lu, B., Hornik, R.: Using Propensity Score Subclassification for Multiple Treatment Doses to Evaluate a National Antidrug Media Campaign. Journal of Educational and Behavioral Statistics 30(1), 15 (2005).

17. European Statistics. Harmonised Index of Consumer Prices.: In. European Commission, (2018)

18. Danford, D.A., Karels, Q., Kutty, S.: Variabilities in the mortality-related resource utilisation for congenital heart disease. Open heart 3(1), e000415 (2016). doi:10.1136/openhrt-2016-000415

19. Willems, R., de Hosson, M., De Backer, J., Annemans, L.: Opinions of general and adult congenital heart disease cardiologists on care for adults with congenital heart disease in Belgium: a qualitative study. Cardiology in the young 29(11), 1368-1374 (2019). doi:10.1017/S1047951119002245

20. Tutarel, O., Kempny, A., Alonso-Gonzalez, R., Jabbour, R., Li, W., Uebing, A., Dimopoulos, K., Swan, L., Gatzoulis, M.A., Diller, G.P.: Congenital heart disease beyond the age of 
60: emergence of a new population with high resource utilization, high morbidity, and high mortality. European heart journal 35(11), 725-732 (2014). doi:10.1093/eurheartj/eht257

21. Verheugt, C.L., Uiterwaal, C.S., van der Velde, E.T., Meijboom, F.J., Pieper, P.G., Sieswerda, G.T., Plokker, H.W., Grobbee, D.E., Mulder, B.J.: The emerging burden of hospital admissions of adults with congenital heart disease. Heart (British Cardiac Society) 96(11), 872-878 (2010). doi:10.1136/hrt.2009.185595

22. Afilalo, J., Therrien, J., Pilote, L., Ionescu-Ittu, R., Martucci, G., Marelli, A.J.: Geriatric congenital heart disease: burden of disease and predictors of mortality. Journal of the American College of Cardiology 58(14), 1509-1515 (2011). doi:10.1016/j.jacc.2011.06.041

23. Neidenbach, R.C., Lummert, E., Vigl, M., Zachoval, R., Fischereder, M., Engelhardt, A., Pujol, C., Oberhoffer, R., Nagdyman, N., Ewert, P., Hauser, M., Kaemmerer, H.: Noncardiac comorbidities in adults with inherited and congenital heart disease: report from a single center experience of more than 800 consecutive patients. Cardiovascular diagnosis and therapy 8(4), 423-431 (2018). doi:10.21037/cdt.2018.03.11

24. Seckeler, M.D., Thomas, I.D., Andrews, J., Meziab, O., Moe, T., Heller, E., Klewer, S.E.: Higher Cost of Hospitalizations for Non-cardiac Diagnoses in Adults with Congenital Heart Disease. Pediatric cardiology 39(3), 437-444 (2018).

25. Zomer, A.C., Verheugt, C.L., Vaartjes, I., Uiterwaal, C.S., Langemeijer, M.M., Koolbergen, D.R., Hazekamp, M.G., van Melle, J.P., Konings, T.C., Bellersen, L., Grobbee, D.E., Mulder, B.J.: Surgery in adults with congenital heart disease. Circulation 124(20), 2195-2201 (2011). doi:10.1161/circulationaha.111.027763

26. Kempny, A., Diller, G.P., Dimopoulos, K., Alonso-Gonzalez, R., Uebing, A., Li, W., BabuNarayan, S., Swan, L., Wort, S.J., Gatzoulis, M.A.: Determinants of outpatient clinic attendance amongst adults with congenital heart disease and outcome. International journal of cardiology 203, 245-250 (2016). doi:10.1016/j.ijcard.2015.10.081

27. BMJ: 348:g1072. (2014). 


\section{FIGURES}

448

Total costs difference - Mild

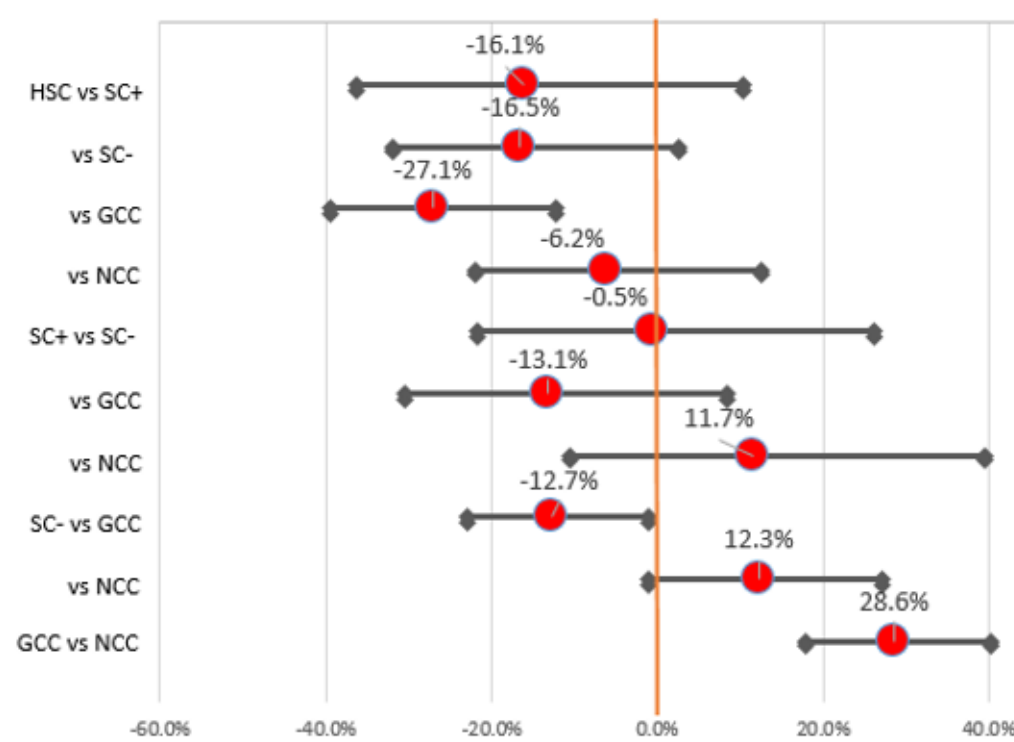

Total costs difference - Moderate

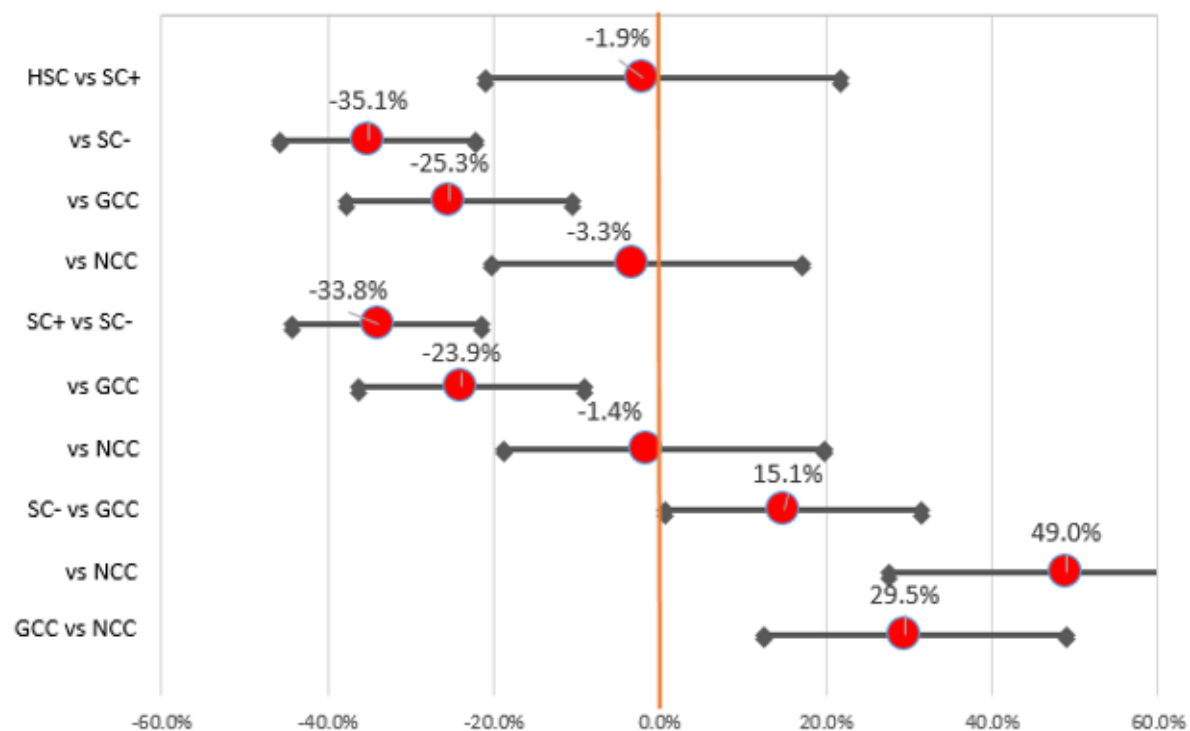

Fig 1 Total medical costs differences between the five care levels for patients with mild and moderate lesions. HSC: highly specialized cardiac care; SC+: shared care with predominantly specialized cardiac care; SC-: shared care with predominantly general cardiac care; GCC: general cardiac care; NCC: no cardiac care. If the confidence interval crosses the orange line, then there is no statistically significant difference on a p-value threshold of 0.05 . A negative percentage means that the cost is lower for patients categorized in the former care level, a positive percentage means that the cost is lower for patients categorized in the latter care level. 

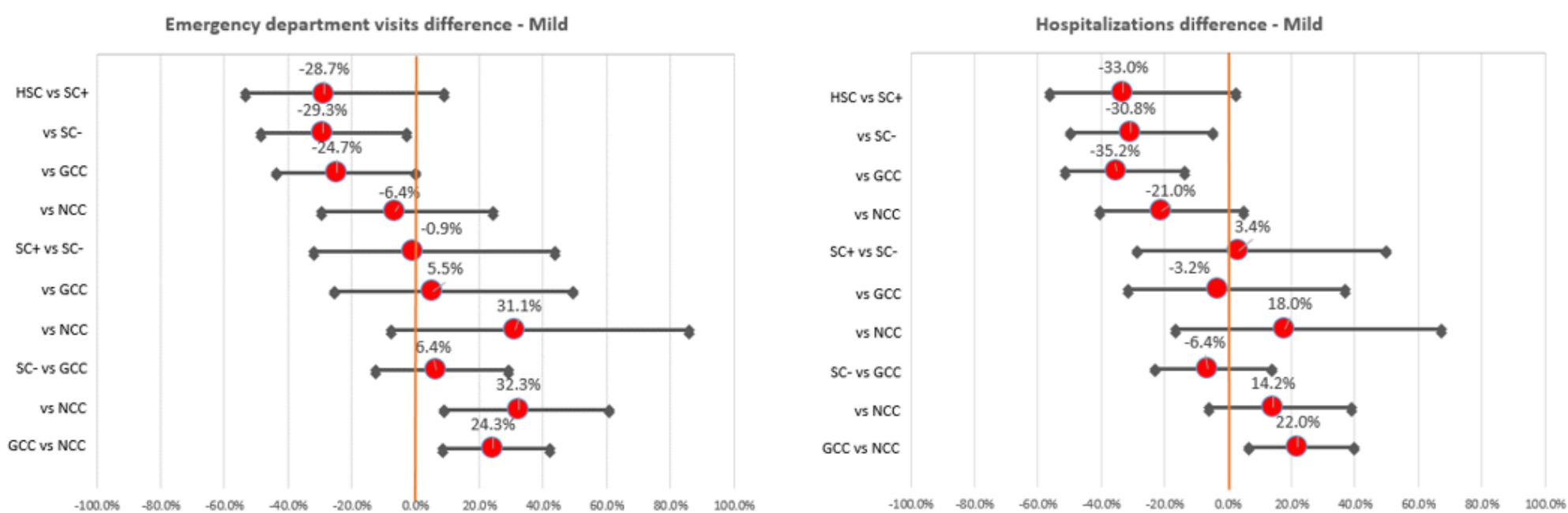

Emergency department visits difference - Moderate
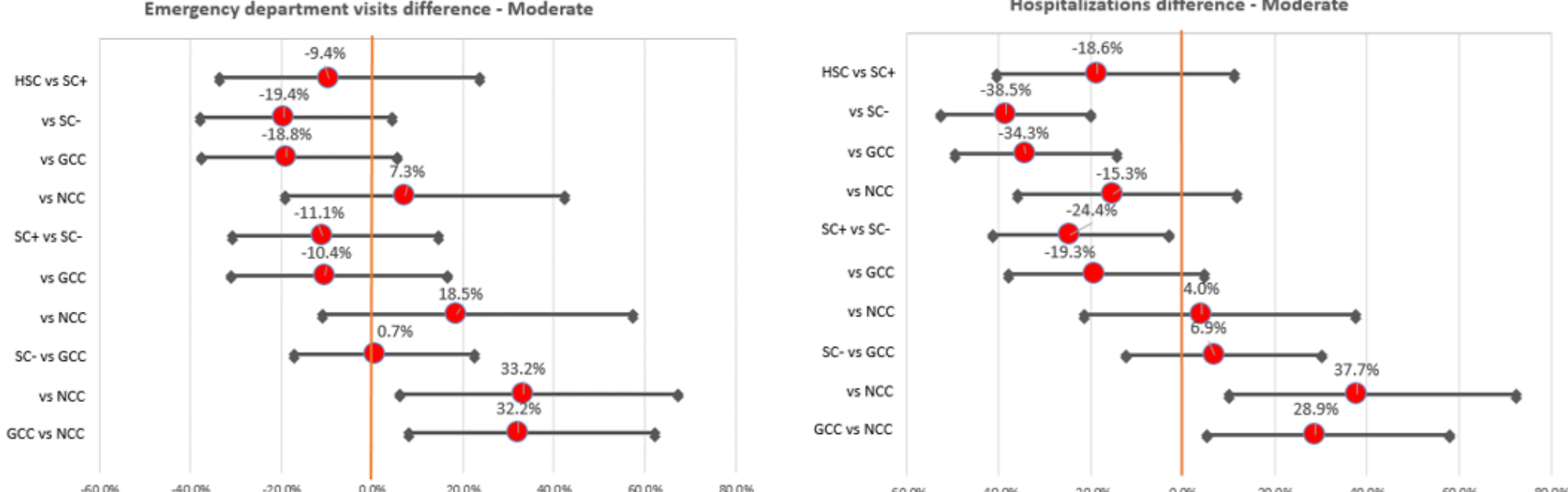

Fig 2 Emergency department visits and hospitalization rate differences between the five care levels for patients with mild and moderate lesions. HSC: highly specialized cardiac care; SC+: shared care with predominantly specialized cardiac care; SC-: shared care with predominantly general cardiac care; GCC: general cardiac care; NCC: no cardiac care. If the confidence interval crosses the orange line, then there is no statistically significant difference on a p-value threshold of 0.05. A negative percentage means that the cost is lower for patients categorized in the former care level, a positive percentage means that the cost is lower for patients categorized in the latter care level. 
452

453 Table 1. Definitions of the five care levels.

\begin{tabular}{lll}
\hline Care level & Abbreviation & Definition \\
\hline Highly specialized cardiac care & HSC & $\begin{array}{l}\geq 1 \% \text { of cardiology visits at the } \\
\text { specialized care level }\end{array}$ \\
Shared care - predominantly & SC+ & $51-80 \%$ of cardiology visits at \\
specialized cardiac care & & the specialized care level \\
Shared care - predominantly & SC- & $1-50 \%$ of cardiology visits at \\
general cardiac care & & the specialized care level \\
General cardiac care & GCC & All cardiology visits at the \\
& & general cardiology care level \\
No cardiac care & NCC & No cardiology visits between \\
& & 2006 and 2010
\end{tabular}


Table 2. Characteristics of the patient population included for final analysis after propensity score matching

\begin{tabular}{|c|c|c|c|c|c|c|}
\hline & \multicolumn{2}{|c|}{ Mild $(N=3,633)$} & \multicolumn{2}{|c|}{ Moderate $(\mathrm{N}=2,727)$} & \multicolumn{2}{|c|}{ Severe (N=219) } \\
\hline & & $\begin{array}{l}\text { Mean } \\
\text { or } \%\end{array}$ & & $\begin{array}{l}\text { Mean } \\
\text { or } \%\end{array}$ & & $\begin{array}{l}\text { Mean } \\
\text { or } \%\end{array}$ \\
\hline Age beginning 2006 & & $38.9 y$ & & $34.1 y$ & & $28.1 y$ \\
\hline \multicolumn{7}{|l|}{ Age Category } \\
\hline \multirow[t]{3}{*}{ beginning 2006} & $18-29 y$ & $34.9 \%$ & & $48.6 \%$ & & $65.8 \%$ \\
\hline & $30-39 y$ & $20.5 \%$ & & $22.3 \%$ & & $29.7 \%$ \\
\hline & $40+y$ & $44.5 \%$ & & $29.1 \%$ & & $4.6 \%$ \\
\hline Sex & Female & $56.8 \%$ & & $48.7 \%$ & & $42.0 \%$ \\
\hline Mortality 2011-2015 & & $2.7 \%$ & & $3.5 \%$ & & $5.5 \%$ \\
\hline \multirow[t]{5}{*}{ Care level } & NCC & $42.2 \%$ & & $20.8 \%$ & & $6.4 \%$ \\
\hline & GCC & $37.8 \%$ & & $30.7 \%$ & & $11.4 \%$ \\
\hline & SC- & $12.1 \%$ & & $27.8 \%$ & & $47.5 \%$ \\
\hline & $\mathrm{SC}+$ & $3.1 \%$ & & $10.7 \%$ & & $23.7 \%$ \\
\hline & $\mathrm{HSC}$ & $4.8 \%$ & & $10.1 \%$ & & $11.0 \%$ \\
\hline \multirow[t]{14}{*}{$\begin{array}{l}\text { Primary Diagnostic } \\
\text { Code }\end{array}$} & $\begin{array}{l}\text { AV } \\
\text { abnormality }\end{array}$ & $9.7 \%$ & TOF & $16.0 \%$ & $\begin{array}{l}\text { UV } \\
\text { physiology }\end{array}$ & $21.9 \%$ \\
\hline & ASD type 2 & $26.5 \%$ & CoA & $16.5 \%$ & $\begin{array}{l}\text { Tricuspid } \\
\text { atresia }\end{array}$ & $1.8 \%$ \\
\hline & VSD & $28.9 \%$ & AVSD & $3.8 \%$ & TOF** & $2.7 \%$ \\
\hline & & & ASD type 1 & $3.7 \%$ & PA with VSD & $0.5 \%$ \\
\hline & $\begin{array}{l}\text { MV } \\
\text { abnormality }\end{array}$ & $8.2 \%$ & Ebstein anomaly & $1.8 \%$ & $\begin{array}{l}\text { PA with } \\
\text { intact } \\
\text { ventricular } \\
\text { septum }\end{array}$ & $1.8 \%$ \\
\hline & Other & $26.6 \%$ & PV abnormality & $20.0 \%$ & DORV & $11.4 \%$ \\
\hline & & & AV abnormality* & $8.5 \%$ & DILV & $0.5 \%$ \\
\hline & & & Aortic abnormality & $11.6 \%$ & TA & $1.8 \%$ \\
\hline & & & LVOT obstruction & $1.0 \%$ & TGA & $48.9 \%$ \\
\hline & & & ASD type $2^{*}$ & $6.3 \%$ & cC-TGA & $8.7 \%$ \\
\hline & & & VSD* & $4.6 \%$ & & \\
\hline & & & MV abnormality* & $1.4 \%$ & & \\
\hline & & & $\begin{array}{l}\text { Pulmonary vein } \\
\text { abnormality }\end{array}$ & $4.6 \%$ & & \\
\hline & & & Other* & $0.4 \%$ & & \\
\hline
\end{tabular}

ASD: atrial septal defect; AV: aortic valve; AVSD: atrioventricular septal defect; CoA: coarctation of the aorta; DILV: double inlet left ventricle; DORV: double outlet right ventricle; LVOT: left ventricular outflow tract; MV: mitral valve; PA: pulmonary atresia PV: pulmonary valve; TGA: transposition of the great arteries; Cc-TGA: congenitally corrected transposition of the great arteries; TOF: tetralogy of Fallot; UV: univentricular; VSD: ventricular septal defect.

GCC: general cardiac care; HSC: highly specialized cardiac care; NCC: no cardiac care; SC-: shared care predominantly general cardiac care; SC+: shared care predominantly specialized cardiac care.

* These diagnoses are moderate defects if they are associated with complications (e.g. pulmonary arterial hypertension with ASD/VSD) or with significant functional abnormalities (valvular dysfunction).

** Uncorrected Tetralogy of Fallot with pulmonary arterial hypertension 


\title{
Supplement S1 Step-by-step statistical analysis and full results
}

\author{
of the paper
}

\section{Different Levels of Care for Follow-up of Adults with Congenital Heart \\ Disease; Impact on Medical Costs, Hospitalizations, and Emergency \\ Department Visits}

\section{Running title: Different Care Levels for ACHD Follow-up}

The analysis conducted in this paper was inspired by a statistical paper from Zanutto et al. ${ }^{1}$ on how to use propensity score subclassification for multiple treatment arms. We followed their lead to a great extent but specific data issues urged for a tailored approach (e.g. how we dealt with missing data, the choice of the number of subclassification groups).

\section{Preparation phase}

Selection of covariates. For every single patient, a propensity score was calculated based on a set of 12 demographic, socio-economic and clinical covariates. Covariates were either categorical or continuous (Table 1).

Table 1. Covariates to calculate the propensity score.

\begin{tabular}{|c|c|c|}
\hline Variables & Description & Coding \\
\hline Self-employment & $\begin{array}{l}\text { Job status: was the patient self- } \\
\text { employed in } 2005 \text { ? }\end{array}$ & $\begin{array}{l}0: \text { No } \\
1: \text { Yes }\end{array}$ \\
\hline Marital status & Marital status in 2005 & $\begin{array}{l}\text { 1: Unmarried } \\
\text { 2: Married } \\
\text { 3: Widow(er) } \\
\text { 4: Divorced }\end{array}$ \\
\hline Household type & Household type 2005 & $\begin{array}{l}\text { 1: Single, children } \\
\text { 2: Single, no children } \\
\text { 3: Partner, children } \\
\text { 4: Partner, no children } \\
\text { 5: Collective household } \\
\text { 6: Other }\end{array}$ \\
\hline $\begin{array}{l}\text { Increased } \\
\text { reimbursement }\end{array}$ & $\begin{array}{l}\text { The patient exceeded in } 2005 \text { a } \\
\text { certain threshold of out-of-pocket } \\
\text { medical costs. }\end{array}$ & $\begin{array}{l}0: \text { No } \\
1: \text { Yes }\end{array}$ \\
\hline Household income & $\begin{array}{l}\text { Patients divided in quartiles based } \\
\text { on household income in } 2005 .\end{array}$ & $\begin{array}{l}0: \text { lower } 25 \% \\
1 \text { : Average lower } 25 \% \\
2: \text { Average higher } 25 \% \\
3: \text { upper } 25 \%\end{array}$ \\
\hline Chronical ill & $\begin{array}{l}\text { The patient had a status of } \\
\text { chronically ill and/or had a } \\
\text { disability allowance in } 2005 \text {. }\end{array}$ & $\begin{array}{l}0: \text { No } \\
1: \text { Yes }\end{array}$ \\
\hline Available caregivers & & Continuous variable \\
\hline
\end{tabular}




\begin{tabular}{|c|c|c|}
\hline $\begin{array}{l}\text { Interventions } \\
\text { Age } \\
\text { Syndrome } \\
\text { Sex } \\
\text { Primary diagnose }\end{array}$ & $\begin{array}{l}\text { Caregiver: someone who's } 25 \text { or } \\
\text { older; at least partially unemployed } \\
\text { or retired; not disabled; not } \\
\text { chronically sick. (minimum number } \\
\text { available in 2005). } \\
\text { Number of interventions pre } 2006 \\
\text { Stratified in three categories } \\
\text { Syndrome (catch 22, trisomy 21, } \\
\text { Noonan, Marfan, Turner, Williams) } \\
\text { Man of woman } \\
\text { Primary diagnostic code }\end{array}$ & $\begin{array}{l}\text { Continuous variable } \\
\text { 1: } 18-29 \text { years old } \\
\text { 2: 30-39 years old } \\
\text { 3: 40-... years old } \\
\text { 0: absent } \\
\text { 1: present } \\
\text { 0: woman } \\
\text { 1: man } \\
\text { 1: Hypoplastic left heart } \\
\text { syndrome } \\
\text { 2: Univentricular physiology } \\
\text { 3: Tricuspid atresia } \\
\text { 4: Tetralogy of Fallot } \\
\text { 5: Pulmonary atresia with } \\
\text { ventricular septal defect } \\
\text { 6: Pulmonary atresia without } \\
\text { ventricular septal defect } \\
\text { 7: Double outlet right } \\
\text { ventricle } \\
\text { 8: Double inlet left ventricle } \\
\text { 9: Truncus arteriosus } \\
\text { 10: Transposition of the } \\
\text { great arteries } \\
\text { 11: Congenitally corrected } \\
\text { transposition of the great } \\
\text { arteries } \\
\text { 12: Coarctation of the aorta } \\
\text { 13: Atrioventricular septal } \\
\text { defect } \\
\text { 14: Atrial septal defect type } \\
\text { 1 } \\
\text { 15: Ebstein malformation } \\
\text { 16: Pulmonary valve } \\
\text { abnormality } \\
\text { 17: Aortic valve abnormality } \\
\text { 18: Aortic abnormality } \\
\text { 19: Left ventricular outflow } \\
\text { tract obstruction } \\
\text { 20: Atrial septal defect type } \\
2 \\
\text { 21: Ventricular septal defect } \\
\text { 22: Mitral valve abnormality }\end{array}$ \\
\hline
\end{tabular}




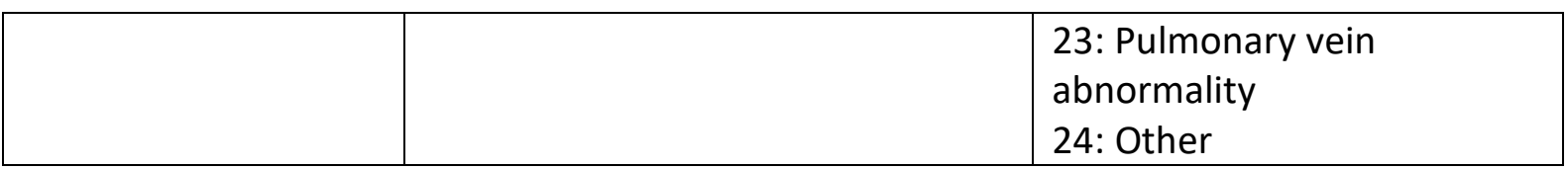

Dealing with missing values. Several covariates had a limited number of missing values. These missing values were found to exist in a limited number of patients ( $n=221,3.08 \%$ ). Patients with missing values were excluded from further analyses, resulting in an initial sample size of 6,959 patients.

Dealing with skewed distribution of covariates. The next step was to look at the covariates' distributions. The distributions of the two continuous variables (number of available caregivers and number of interventions) were characterized by an extreme skewness. Therefore, the square roots of these covariates were calculated and used as covariates to calculate the propensity score.

Further analyses were stratified for adult patients with either mild, moderate or severe lesions. The respective sample size before propensity score subclassification was 3,744 (53.8\%), 2,889 (41.5\%), and $326(4.7 \%)$ patients.

\section{Analysis phase}

Step 1. An Ordinal Logit Model was constructed with care level as the dependent variable and the main effects of the 12 covariates (Table 1 ) as independent variables. A propensity score was calculated per patient. The propensity score can be interpreted as the theoretical chance of being treated in the highest of five care level (Table 2).

Table 2. Definitions of the five care levels. Cardiology visits between 2006 and 2010 were taken into account.

\begin{tabular}{|c|c|c|}
\hline Care level & Abbreviation & Definition \\
\hline 4: Highly specialized care & HSC & $\begin{array}{l}\geq 81 \% \text { of cardiology visits at the } \\
\text { specialized care level }\end{array}$ \\
\hline $\begin{array}{l}\text { 3: Shared care - predominantly } \\
\text { specialized care }\end{array}$ & $\mathrm{SC}+$ & $\begin{array}{l}51-80 \% \text { of cardiology visits at } \\
\text { the specialized care level }\end{array}$ \\
\hline $\begin{array}{l}\text { 2: Shared care-predominantly } \\
\text { general care }\end{array}$ & SC- & $\begin{array}{l}1-50 \% \text { of cardiology visits at } \\
\text { the specialized care level }\end{array}$ \\
\hline 1: General cardiac care & GCC & $\begin{array}{l}\text { All cardiology visits at the } \\
\text { general cardiology care level }\end{array}$ \\
\hline 0: No cardiac care & NCC & $\begin{array}{l}\text { No cardiology visits between } \\
2006 \text { and } 2010\end{array}$ \\
\hline
\end{tabular}


Step 2. The minimum and maximum propensity score per exposure level was checked. The highest minimum score and the lowest maximum score were taken to define the boundaries (=the region of overlap). Patients with a propensity score lower than the minimum score or higher than the maximum score were deleted from further analysis. For example:

\begin{tabular}{lrr} 
& \multicolumn{2}{c}{ Range } \\
& Minimum & Maximum \\
\cline { 2 - 3 } Care level 0 & 0.05 & $\mathbf{0 . 4 0}$ \\
Care level 1 & 0.02 & 0.55 \\
Care level 2 & 0.06 & 0.45 \\
Care level 3 & $\mathbf{0 . 1 5}$ & 0.50 \\
Care level 4 & 0.10 & 0.56
\end{tabular}

In this example the region of overlap is $0.15-0.40$. Patients with a propensity score below 0.15 or above 0.40 were excluded from further analysis, and therefore called the 'excluded low group' and 'the excluded high group' respectively.

Step 3. Included patients with mild or moderate lesions were categorized into ten equally sized deciles. Patients with severe lesions were categorized into five equally sized quintiles because of the lower sample size. More groups lead to less imbalance, but it has been demonstrated that the use of quintiles already reduces the existing imbalance with $90 \%^{1-3}$. This resulted in patients being categorized in either a $10 \times 5$ or $5 \times 5$ matrix:

\begin{tabular}{|l|l|l|l|l|l|}
\hline & \multicolumn{5}{|c|}{ Care level 1-5 } \\
\hline \multirow{4}{*}{$\begin{array}{l}\text { Quintiles 1-5 } \\
\text { or deciles 1-5 }\end{array}$} & & & & & \\
\cline { 2 - 6 } & & & & & \\
\cline { 2 - 6 } & & & & & \\
\hline \multirow{4}{*}{ Deciles 6-10 } & & & & & \\
\cline { 2 - 6 } & & & & & \\
\cline { 2 - 6 } & & & & & \\
\cline { 2 - 6 } & & & & & \\
\cline { 2 - 6 } & & & & & \\
\hline
\end{tabular}

Step 4. We checked if any imbalance existed between the five care levels. A Two-Way Anova for continuous variables or a logistic regression for non-continuous variables was modelled with the covariate as dependent variable. Independent variables were the quintile rank, the 
care level, and the interaction variable. If the care level or the interaction was significant on a p-value threshold of 0.05 , imbalance between care levels existed.

Step 5. An iterative process started with the replication of Step 1 to Step 4, with the difference that in Step 1 an Ordinal Logit Model was constructed with care level as the dependent variable and the main effects of the 12 covariates as independent variables, plus the addition of one or more independent variables: the quadratic or interaction of variables with imbalance were added. The aim was not to have a parsimonious model but to reach as much balance as possible.

Step 6. Summary statistics of the included and excluded patients were checked using the Kruskal Wallis Test with Dwass, Steel, Critchlow-Fligner (DSCF) test for multiple comparisons ( $P$-value $\leq 0.05)$. As the analysis was restricted to the region of overlap, obtained results can only be applied on the subpopulation represented by this region of overlap.

Step 7. Outcomes were calculated with following formulas:

$$
Y j=\sum_{i}^{5 \text { or } 10} \frac{1}{5 \text { or } 10} Y i j
$$

with $\mathrm{Yj}=$ the weighted outcome of patients in care level $\mathrm{j} ; \mathrm{Yij}=$ the average outcome of patients in care level $\mathrm{j}$ and quintile/decile $\mathrm{i}$. In other words: each quintile/decile had an equal weight in the calculation of the average outcome per care level.

$$
S E(Y j)=\frac{1}{5 \text { or } 10} \sqrt{\sum_{i}^{5 \text { or } 10} \frac{S i j^{\wedge} 2}{N i j}}
$$

with $\mathrm{SE}(\mathrm{Yj})=$ the standard error of the outcome in care level $\mathrm{j} ; \mathrm{Sij}^{\wedge} \mathbf{2}=$ the variance in quintile/decile $\mathrm{i}$ of care level $\mathrm{j}$; $\mathrm{Nij}=$ the number of patients in quintile/decile $\mathrm{i}$ of care level $\mathrm{j}$.

Results were calculated using regression models with the outcome as dependent variable and the care level as independent variable. The regression models were adjusted for the propensity score quintile/decile and, if covariate imbalance could not be avoided, for the covariates with remaining imbalance ${ }^{4}$.

Outcomes were measured in a five year period from 2011 to 2015: total medical costs, total hospitalization costs, total outpatient costs, total pharmaceutical costs, emergency department (ED) visits, and the number of hospitalizations (all calculated per patient year). In particular, we calculated the difference (in percentages) between the five different care levels. 


\section{Adult patients with mild lesions}

It appeared to be infeasible to delete all imbalance by adding quadratics and interactions. The final Ordinal Logit Model with 12 main effects, one quadratic effect (i.e. number of interventions), and nine interaction effects (i.e. number of interventions*age category, number of interventions*primary diagnose, marital status*household type, household type*household income, age category*household income, age category*marital status, age category*household type, marital status*available caregivers, household type*available caregivers) resulted in remaining imbalance in 6 out of the 12 covariates (i.e. marital status, household type, household income, primary diagnose, age category, and number of interventions). These covariates were added to the final regression model to adjust the impact of care level on the respective outcomes.

Table 3 shows how the excluded patients $(\mathrm{N}=111,3.0 \%)$ differed from the included patients $(\mathrm{N}=3,633,97 \%)$. The results did not apply on (i) a small group of patients who can be characterized by having had less available informal caregivers and less interventions, a lower household income, a lower age, with more widow(er)s, a smaller proportion of patients with a partner but no children, and more ventricular septal defect (VSD) as a primary diagnose. And (ii) a small group of patients who can be characterized by having had more interventions, be chronical ill, a greater proportion of males, being unmarried, and who were primarily diagnosed with an aortic valve (AV) abnormality.

Table 3. Covariates, care level, and outcomes of included and excluded patients with mild lesions.

\begin{tabular}{|c|c|c|c|c|}
\hline & & $\begin{array}{l}\text { Excluded } \\
\text { low }(\mathrm{N}=51) \\
\text { Mean/\% }\end{array}$ & $\begin{array}{c}\text { Included } \\
(\mathrm{N}=3,633) \\
\text { Mean/\% }\end{array}$ & $\begin{array}{l}\text { Excluded } \\
\text { High }(\mathrm{N}=60) \\
\text { Mean/\% }\end{array}$ \\
\hline $\begin{array}{l}V \text { (number of available informal } \\
\text { caregivers) }\end{array}$ & & $0.17^{*}$ & 0.40 & 0.47 \\
\hline$V($ number of interventions) & & $0.13^{*}$ & 0.34 & $1.52^{*}$ \\
\hline Self-employment & & $10 \%$ & $9 \%$ & $5 \%$ \\
\hline Increased reimbursement & & $4 \%$ & $10 \%$ & $17 \%$ \\
\hline Chronical ill & & $2 \%$ & $7 \%$ & $20 \% *$ \\
\hline Syndrome & & $0 \%$ & $3 \%$ & $5 \%$ \\
\hline Income rank (quartiles) & & $0.78^{*}$ & 1.56 & 1.60 \\
\hline Age category & & $1.82 *$ & 2.10 & 1.88 \\
\hline Gender (male) & & $43 \%$ & $43 \%$ & $65 \% *$ \\
\hline \multirow[t]{4}{*}{ Marital status } & Unmarried & $59 \%$ & $45 \%$ & $65 \% *$ \\
\hline & Married & $27 \% *$ & $47 \%$ & $33 \%$ \\
\hline & Widow(er) & $10 \% *$ & $2 \%$ & $0 \%$ \\
\hline & Divorced & $4 \%$ & $6 \%$ & $2 \%$ \\
\hline \multirow[t]{6}{*}{ Household type } & Single, children & $29 \% *$ & $8 \%$ & $12 \%$ \\
\hline & Single, no children & $24 \% *$ & $9 \%$ & $2 \%$ \\
\hline & Partner, children & $16 \%$ & $21 \%$ & $22 \%$ \\
\hline & Partner, no children & $20 \% *$ & $61 \%$ & $57 \%$ \\
\hline & Collective household & $2 \% *$ & $0 \%$ & $5 \% *$ \\
\hline & Other & $10 \% *$ & $1 \%$ & $3 \%$ \\
\hline \multirow[t]{2}{*}{ Primary diagnostic code } & AV abnormality & $0 \% *$ & $10 \%$ & $88 \% *$ \\
\hline & ASD 2 & $12 \% *$ & $27 \%$ & $2 \% *$ \\
\hline
\end{tabular}


Care level

VSD

$88 \% *$

$29 \%$

$0 \% *$

MV abnormality

$0 \%$

$8 \%$

$5 \%$

Other

$0 \% *$

$27 \%$

$5 \% *$

Emergency department visits (per PY)

$0.37 *$

0.90

$2.05^{*}$

Hospitalizations (per PY)

0.34

0.23

0.24

Hospitalization cost (per PY)

0.24

0.29

0.33

Pharmaceutical costs (per PY)

$1424 €$

$2082 €$

$2092 €$

Ambulant costs (per PY)

$488 €$

$823 €$

$1179 €$

Total medical costs (per PY)

$1552 €$

$1763 €$

$2492 €$

$3464 €$

$4668 €$

$5763 €$

*=significantly different from the included group. ASD 2: atrial septal defect type 2; AV: aortic valve; MV: mitral valve; PH: pulmonary hypertension; PY: patient year; VSD: ventricular septal defect. Care level: from 0 (general care) to 4 (highly specialized care) Income rank: 0 (lowest quartile) to 3 (highest quartile). Age category: 1=1829 years old, 2=30-39 years old, 3=40+ years old. 


\section{Total costs difference}

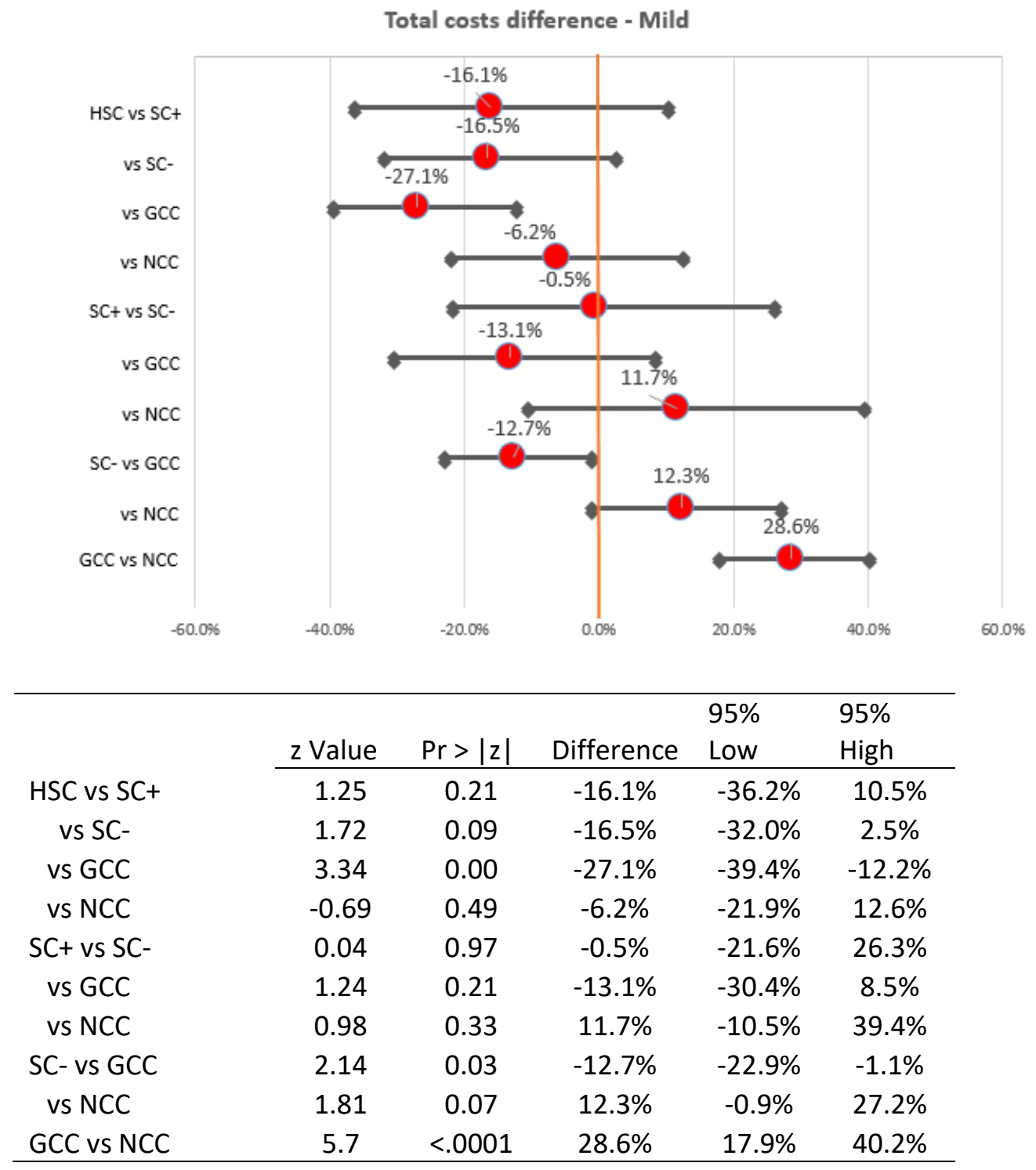




\section{Hospitalization costs difference}

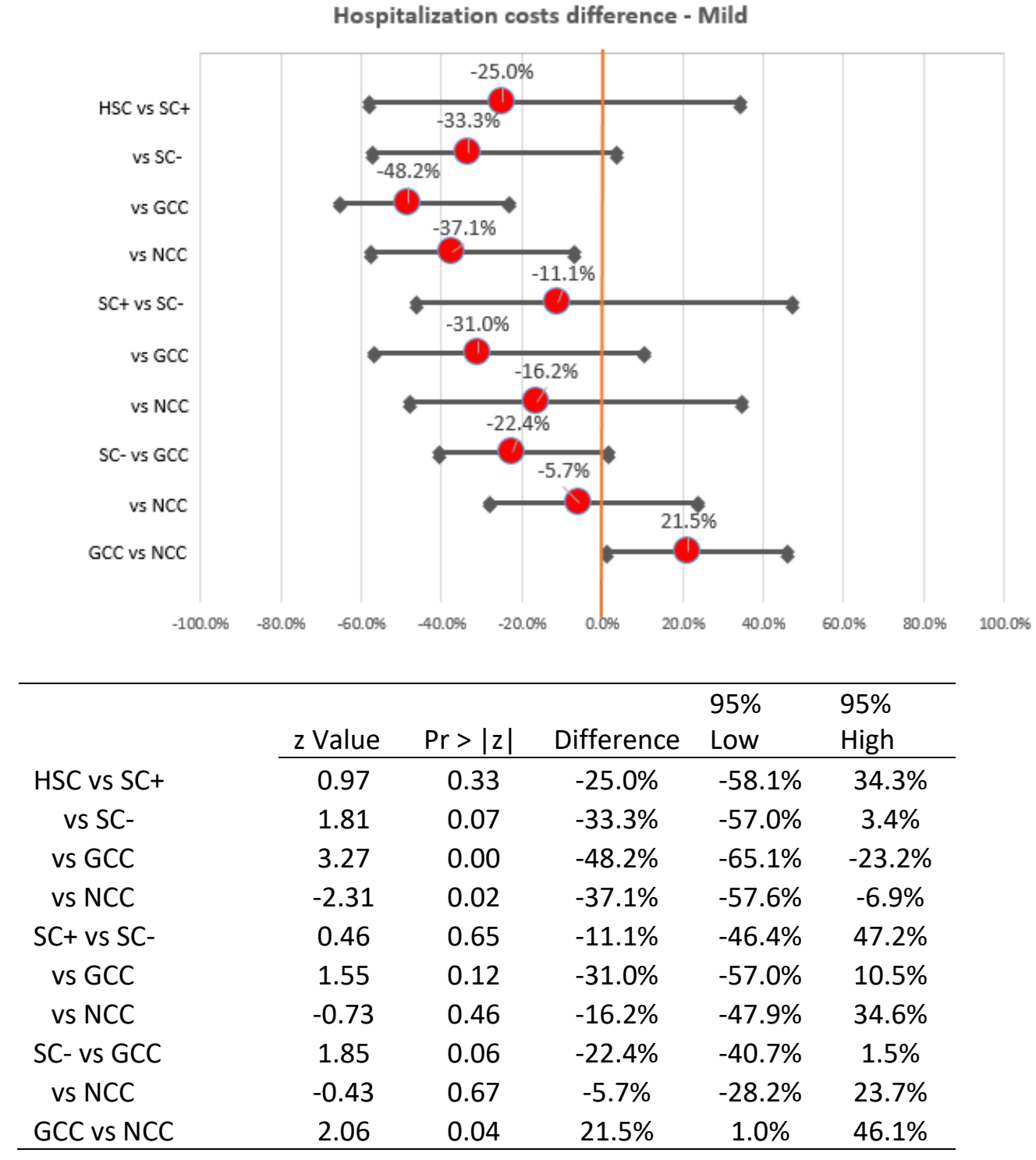


Outpatient costs difference

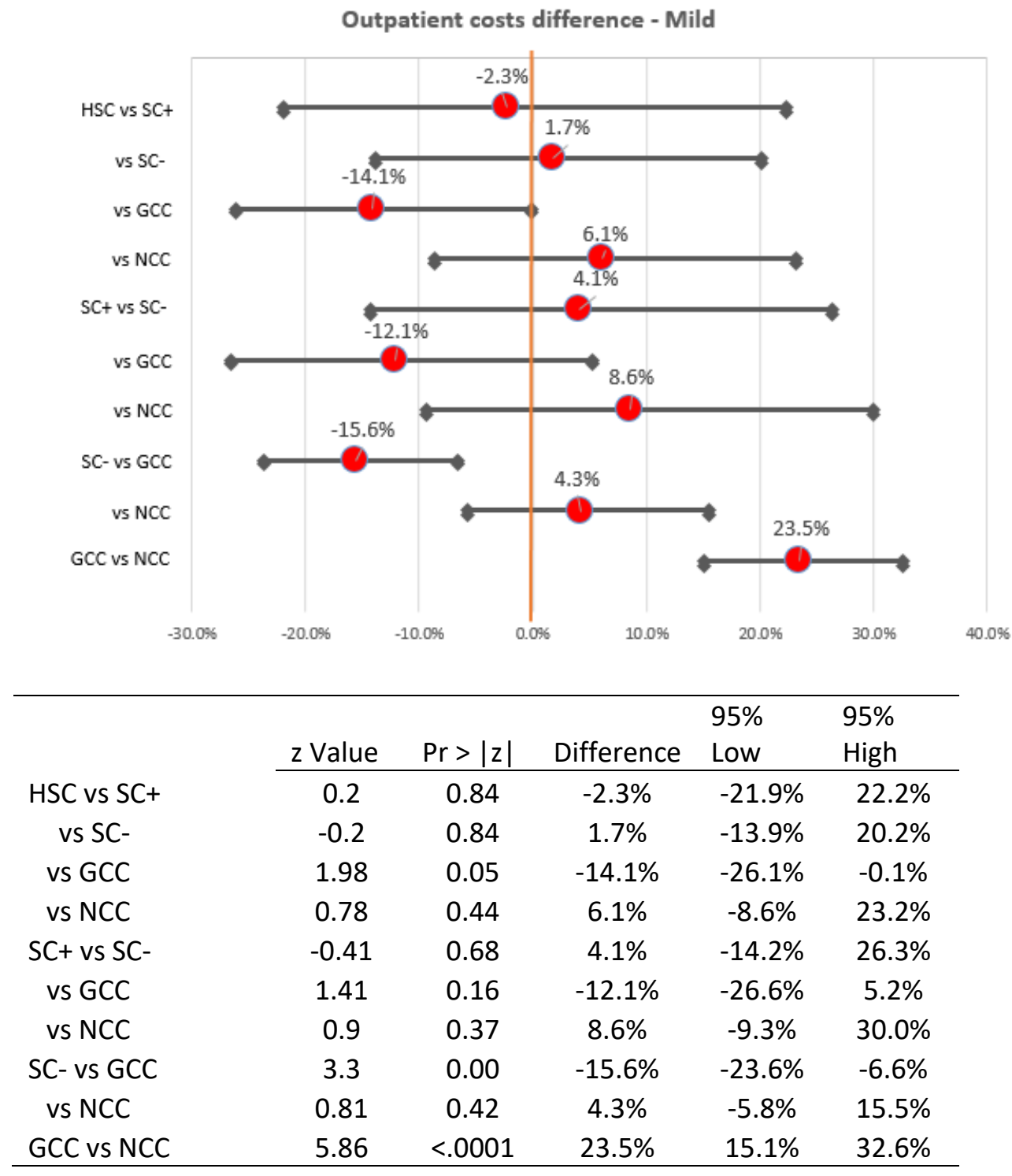


Pharmaceuticals costs difference

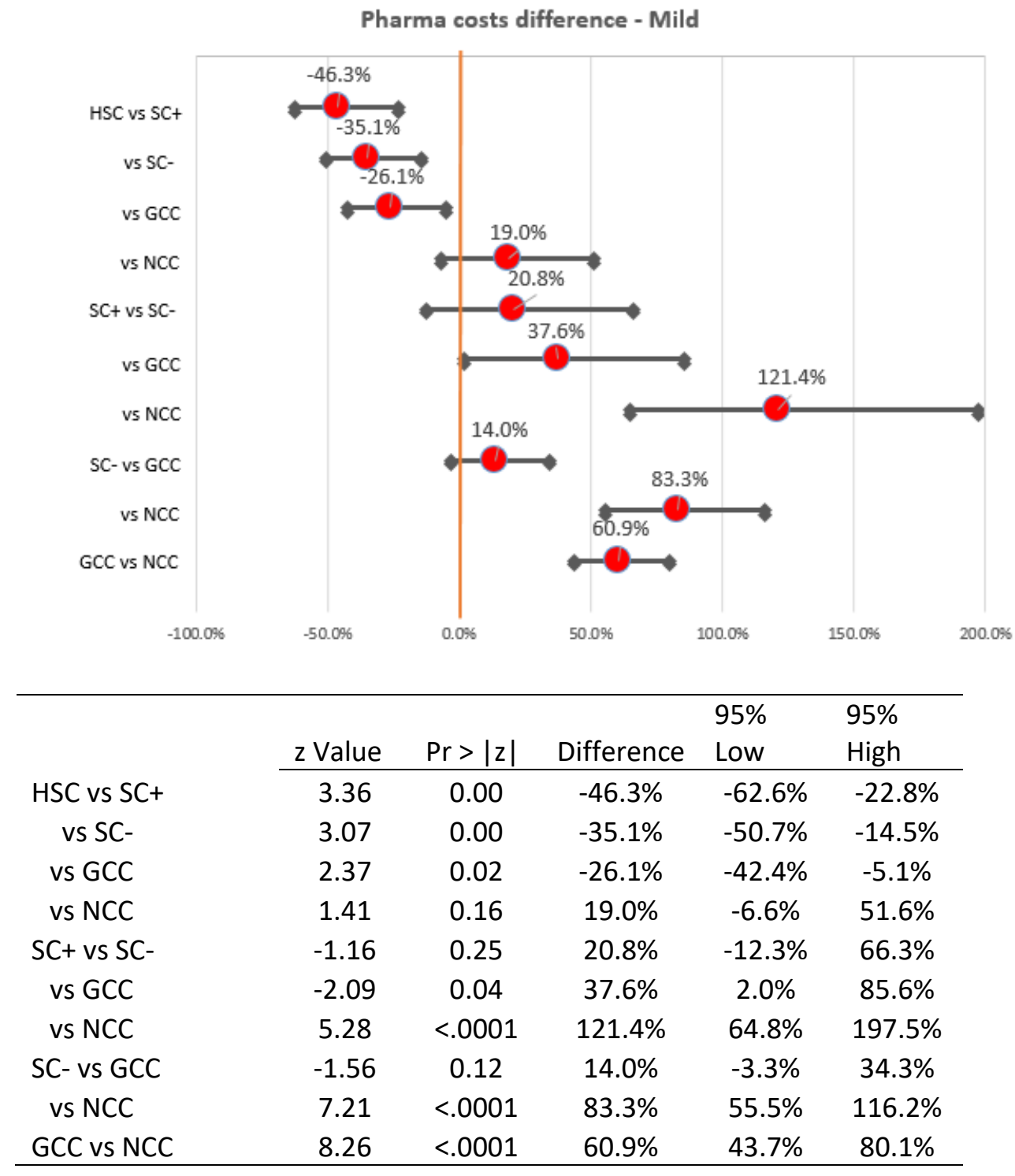




\section{Emergency department visits difference}

Emergency department visits difference - Mild

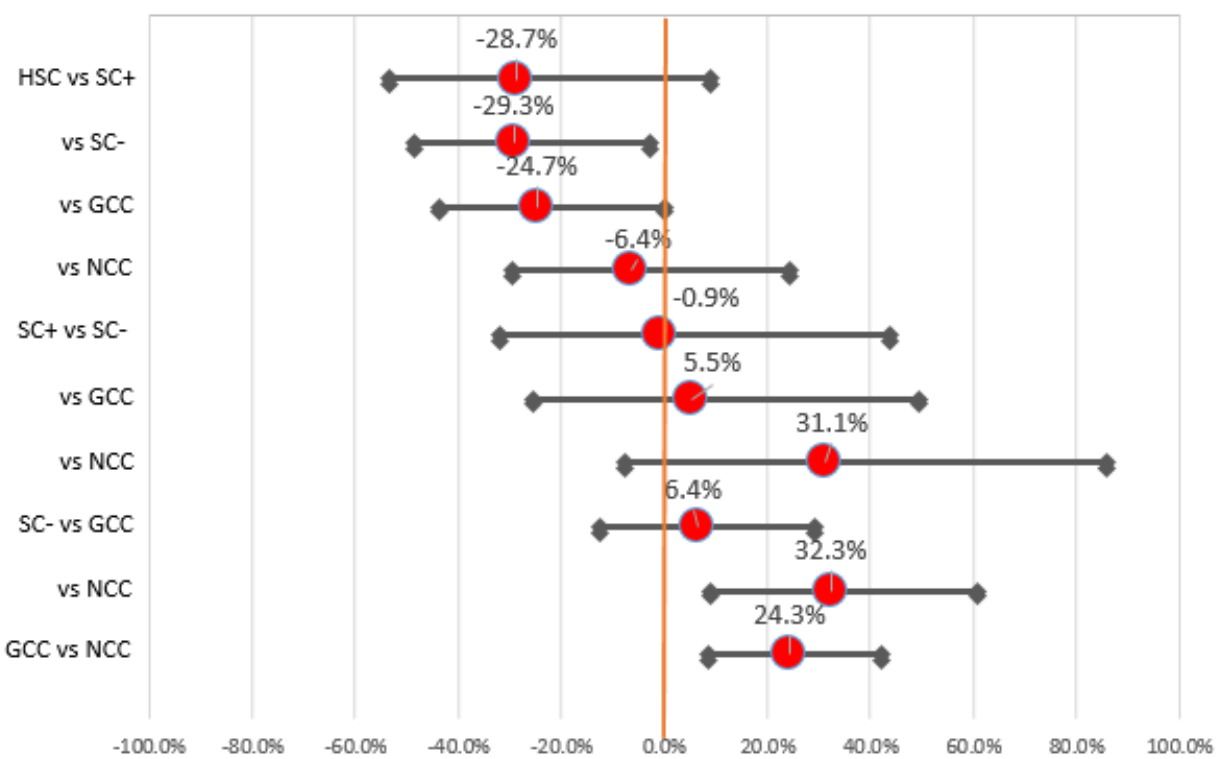

\begin{tabular}{cccccc}
\hline & & & & $95 \%$ & $95 \%$ \\
& $z$ Value & $\operatorname{Pr}>|z|$ & Difference & Low & High \\
\cline { 2 - 6 } HSC vs SC+ & 1.56 & 0.12 & $-28.7 \%$ & $-53.3 \%$ & $8.9 \%$ \\
vs SC- & 2.14 & 0.03 & $-29.3 \%$ & $-48.5 \%$ & $-2.9 \%$ \\
vs GCC & 1.94 & 0.05 & $-24.7 \%$ & $-43.5 \%$ & $0.3 \%$ \\
vs NCC & -0.46 & 0.65 & $-6.4 \%$ & $-29.6 \%$ & $24.4 \%$ \\
SC+ vs SC- & 0.05 & 0.96 & $-0.9 \%$ & $-31.7 \%$ & $43.9 \%$ \\
vs GCC & -0.3 & 0.76 & $5.5 \%$ & $-25.4 \%$ & $49.3 \%$ \\
vs NCC & 1.52 & 0.13 & $31.1 \%$ & $-7.4 \%$ & $85.7 \%$ \\
SC- vs GCC & -0.63 & 0.53 & $6.4 \%$ & $-12.4 \%$ & $29.3 \%$ \\
vs NCC & 2.82 & 0.00 & $32.3 \%$ & $8.9 \%$ & $60.7 \%$ \\
GCC vs NCC & 3.15 & 0.00 & $24.3 \%$ & $8.6 \%$ & $42.3 \%$ \\
\hline
\end{tabular}


Hospitalizations difference - Mild

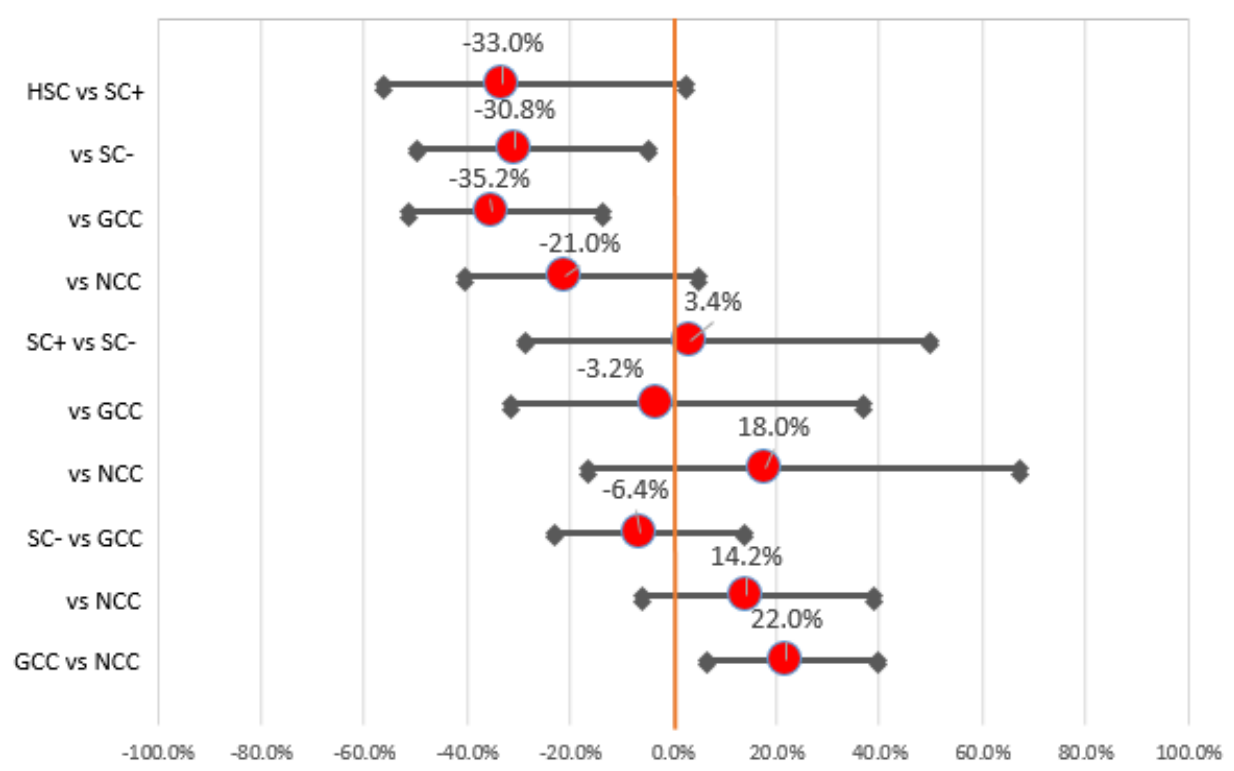

\begin{tabular}{cccccc}
\hline & & & & $95 \%$ & $95 \%$ \\
& $z$ Value & $\operatorname{Pr}>|z|$ & Difference & Low & High \\
\cline { 2 - 6 } HSC vs SC+ & 1.84 & 0.07 & $-33.0 \%$ & $-56.3 \%$ & $2.6 \%$ \\
vs SC- & 2.26 & 0.02 & $-30.8 \%$ & $-49.7 \%$ & $-4.8 \%$ \\
vs GCC & 2.96 & 0.00 & $-35.2 \%$ & $-51.4 \%$ & $-13.7 \%$ \\
vs NCC & -1.62 & 0.11 & $-21.0 \%$ & $-40.5 \%$ & $5.1 \%$ \\
SC+ vs SC- & -0.17 & 0.86 & $3.4 \%$ & $-28.6 \%$ & $49.7 \%$ \\
vs GCC & 0.19 & 0.85 & $-3.2 \%$ & $-31.5 \%$ & $36.7 \%$ \\
vs NCC & 0.93 & 0.35 & $18.0 \%$ & $-16.6 \%$ & $67.1 \%$ \\
SC- vs GCC & 0.66 & 0.51 & $-6.4 \%$ & $-23.0 \%$ & $13.8 \%$ \\
vs NCC & 1.33 & 0.18 & $14.2 \%$ & $-6.1 \%$ & $38.8 \%$ \\
GCC vs NCC & 2.86 & 0.00 & $22.0 \%$ & $6.5 \%$ & $39.8 \%$ \\
\hline
\end{tabular}




\section{Adult patients with moderate lesions}

It appeared to be infeasible to delete all imbalance by adding quadratics and interactions. The final Ordinal Logit Model with 12 main effects, and six interaction effects (i.e. number of interventions*age category, age category*household type, age category*primary diagnostic code, number of interventions*primary diagnose, household type*household income, household type*available caregivers, available caregivers*household income) resulted in remaining imbalance in 5 out of the 12 covariates (i.e. household type, household income, primary diagnose, syndrome, and number of interventions). These covariates were added to the final regression model to adjust the impact of care level on the respective outcomes.

Table 4 shows how the excluded patients $(\mathrm{N}=162,5.6 \%)$ differed from the included patients $(\mathrm{N}=2,727,94.4 \%)$. The results does not apply on (i) a small group of patients who can be characterized by having had less interventions, having no syndrome, being older, with a different marital status, living more in a collective household, and having a pulmonary valve abnormality or a pulmonary vein abnormality as a primary diagnose. These patients experienced a higher care level on average. And (ii) a small group of patients who could have been characterized by having had more interventions, being more self-employed, being more entitled for an increased reimbursement, suffering more from a syndrome, being younger, being unmarried, living more in a collective household, and who were relatively more diagnosed primarily with an atrial septal defect type 1, an Ebstein malformation, or a left ventricular outflow tract obstruction. These patients experienced a higher care level on average.

Table 4. Covariates, care level, and outcomes of included and excluded patients with moderate lesions.

\begin{tabular}{|c|c|c|c|c|}
\hline & & $\begin{array}{l}\text { Excluded low } \\
(\mathrm{N}=147)\end{array}$ & $\begin{array}{l}\text { Included } \\
(\mathrm{N}=2,727)\end{array}$ & $\begin{array}{l}\text { Excluded High } \\
(\mathrm{N}=15)\end{array}$ \\
\hline & & Mean/\% & Mean/\% & Mean/\% \\
\hline \multicolumn{2}{|c|}{$\begin{array}{l}\mathrm{V} \text { (number of available informal } \\
\text { caregivers) }\end{array}$} & 0.39 & 0.41 & 0.63 \\
\hline \multicolumn{2}{|l|}{$\checkmark$ (number of interventions) } & $0.05^{*}$ & 0.80 & $1.84^{*}$ \\
\hline \multicolumn{2}{|l|}{ Self-employment } & $3 \%$ & $8 \%$ & $27 \% *$ \\
\hline \multicolumn{2}{|l|}{ Increased reimbursement } & $15 \%$ & $16 \%$ & $47 \% *$ \\
\hline \multicolumn{2}{|l|}{ Chronical ill } & $7 \%$ & $14 \%$ & $33 \%$ \\
\hline \multicolumn{2}{|l|}{ Syndrome } & $0 \% *$ & $16 \%$ & $53 \% *$ \\
\hline \multicolumn{2}{|l|}{ Income rank (quartiles) } & 1.54 & 1.53 & 1.13 \\
\hline \multicolumn{2}{|l|}{ Age category } & $2.37^{*}$ & 1.80 & $1.07^{*}$ \\
\hline \multicolumn{2}{|l|}{ Sex (men) } & $46 \%$ & $51 \%$ & $60 \%$ \\
\hline \multirow[t]{4}{*}{ Marital status } & Unmarried & $33 \% *$ & $62 \%$ & $100 \% *$ \\
\hline & Married & $53 \% *$ & $32 \%$ & $0 \% *$ \\
\hline & Widow(er) & $1 \%$ & $1 \%$ & $0 \%$ \\
\hline & Divorced & $14 \% *$ & $4 \%$ & $0 \%$ \\
\hline \multirow[t]{6}{*}{ Household type } & Single, children & $12 \%$ & $10 \%$ & $7 \%$ \\
\hline & Single, no children & $12 \%$ & $10 \%$ & $0 \%$ \\
\hline & Partner, children & $14 \%$ & $18 \%$ & $0 \%$ \\
\hline & Partner, no children & $57 \%$ & $61 \%$ & $67 \%$ \\
\hline & Collective household & $2 \% *$ & $0 \%$ & $13 \% *$ \\
\hline & Other & $3 \%$ & $1 \%$ & $13 \% *$ \\
\hline Primary diagnostic code & TOF & $1 \% *$ & $16 \%$ & $20 \%$ \\
\hline
\end{tabular}




\begin{tabular}{|c|c|c|c|}
\hline CoA & $1 \% *$ & $16 \%$ & $7 \%$ \\
\hline AVSD & $0 \% *$ & $4 \%$ & $0 \%$ \\
\hline ASD 1 & $0 \% *$ & $4 \%$ & $27 \% *$ \\
\hline \multicolumn{4}{|l|}{ Ebstein } \\
\hline malformation & $0 \%$ & $2 \%$ & $13 \% *$ \\
\hline PV abnormality & $76 \% *$ & $20 \%$ & $13 \%$ \\
\hline AV abnormality & $0 \% *$ & $9 \%$ & $0 \%$ \\
\hline Aortic abnormality & $2 \% *$ & $12 \%$ & $7 \%$ \\
\hline LVOT obstruction & $1 \%$ & $1 \%$ & $13 \% *$ \\
\hline ASD 2 & $1 \% *$ & $6 \%$ & $0 \%$ \\
\hline VSD & $1 \%$ & $5 \%$ & $0 \%$ \\
\hline MV abnormality & $0 \%$ & $1 \%$ & $0 \%$ \\
\hline $\begin{array}{l}\text { Pulmonary vein } \\
\text { abnormality }\end{array}$ & $17 \% *$ & $5 \%$ & $0 \%$ \\
\hline \multirow[t]{8}{*}{ Other } & $1 \%$ & $0 \%$ & $0 \%$ \\
\hline & $0.63^{*}$ & 0.49 & $0.77^{*}$ \\
\hline & 0.20 & 0.14 & 0.25 \\
\hline & 0.24 & 0.17 & 0.30 \\
\hline & $1593 €$ & $1006 €$ & $2179 €$ \\
\hline & $552 €$ & $327 €$ & $778 €$ \\
\hline & $1417 €$ & $1078 €$ & $1755 €$ \\
\hline & $3562 €$ & $2618 €$ & $4506 €$ \\
\hline
\end{tabular}

Care level

Emergency department visits (per PY)

Hospitalizations (per PY)

Hospitalization cost (per PY)

Pharmaceutical costs (per PY)

Outpatient costs (per PY)

$3562 €$

$2618 €$

$4506 €$

*=significantly different from the included group. ASD 1: atrial septal defect type 1; ASD 2: atrial septal defect 2; AV: aortic valve; AVSD: atrioventricular septal defect; CoA: coarctation of the aorta; LVOT left ventricular outflow track; MV: mitral valve; PV: pulmonary valve; PY: patient year TOF: tetralogy of Fallot; VSD: ventricular septal defect. Care level: from 0 (general care) to 4 (highly specialized care) Income rank: 0 (lowest quartile) to 3 (highest quartile). Age category: $1=18-29$ years old, $2=30-39$ years old, $3=40+$ years old. 


\section{Total costs difference}

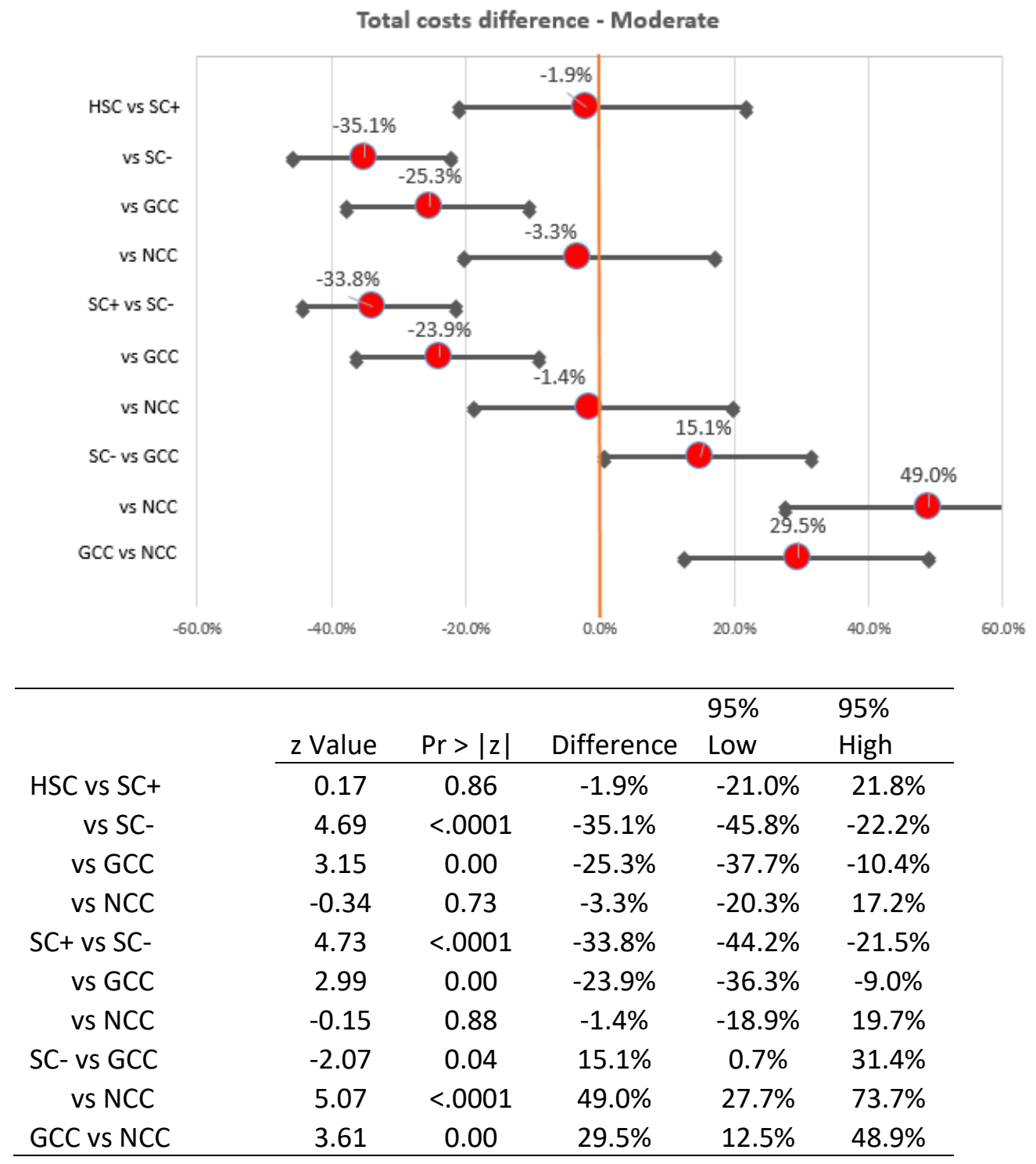




\section{Hospitalization costs difference}

Hospitalization costs difference - Moderate

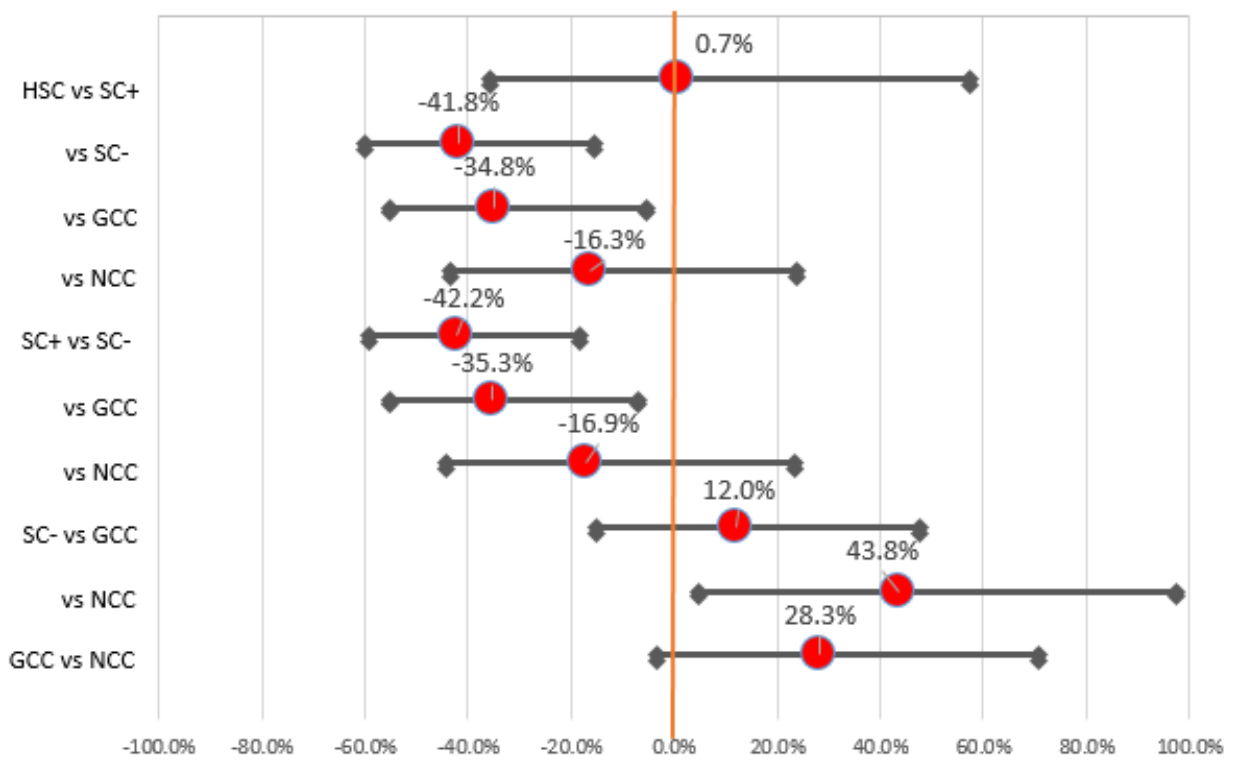

\begin{tabular}{rccccc}
\hline & & & & $95 \%$ & $95 \%$ \\
& $z$ Value & $\operatorname{Pr}>|z|$ & Difference & Low & High \\
\cline { 2 - 6 } HSC vs SC+ & -0.03 & 0.98 & $0.7 \%$ & $-35.6 \%$ & $57.4 \%$ \\
vs SC- & 2.83 & 0.00 & $-41.8 \%$ & $-60.0 \%$ & $-15.4 \%$ \\
vs GCC & 2.24 & 0.03 & $-34.8 \%$ & $-55.2 \%$ & $-5.2 \%$ \\
vs NCC & -0.89 & 0.37 & $-16.3 \%$ & $-43.4 \%$ & $23.7 \%$ \\
SC+ vs SC- & 3.12 & 0.00 & $-42.2 \%$ & $-59.1 \%$ & $-18.5 \%$ \\
vs GCC & 2.34 & 0.02 & $-35.3 \%$ & $-55.0 \%$ & $-6.8 \%$ \\
vs NCC & -0.92 & 0.36 & $-16.9 \%$ & $-44.0 \%$ & $23.4 \%$ \\
SC- vs GCC & -0.81 & 0.42 & $12.0 \%$ & $-15.0 \%$ & $47.6 \%$ \\
vs NCC & 2.25 & 0.02 & $43.8 \%$ & $4.8 \%$ & $97.2 \%$ \\
GCC vs NCC & 1.72 & 0.09 & $28.3 \%$ & $-3.5 \%$ & $70.6 \%$ \\
\hline
\end{tabular}




\section{Outpatient costs difference}

Outpatient costs difference - Moderate

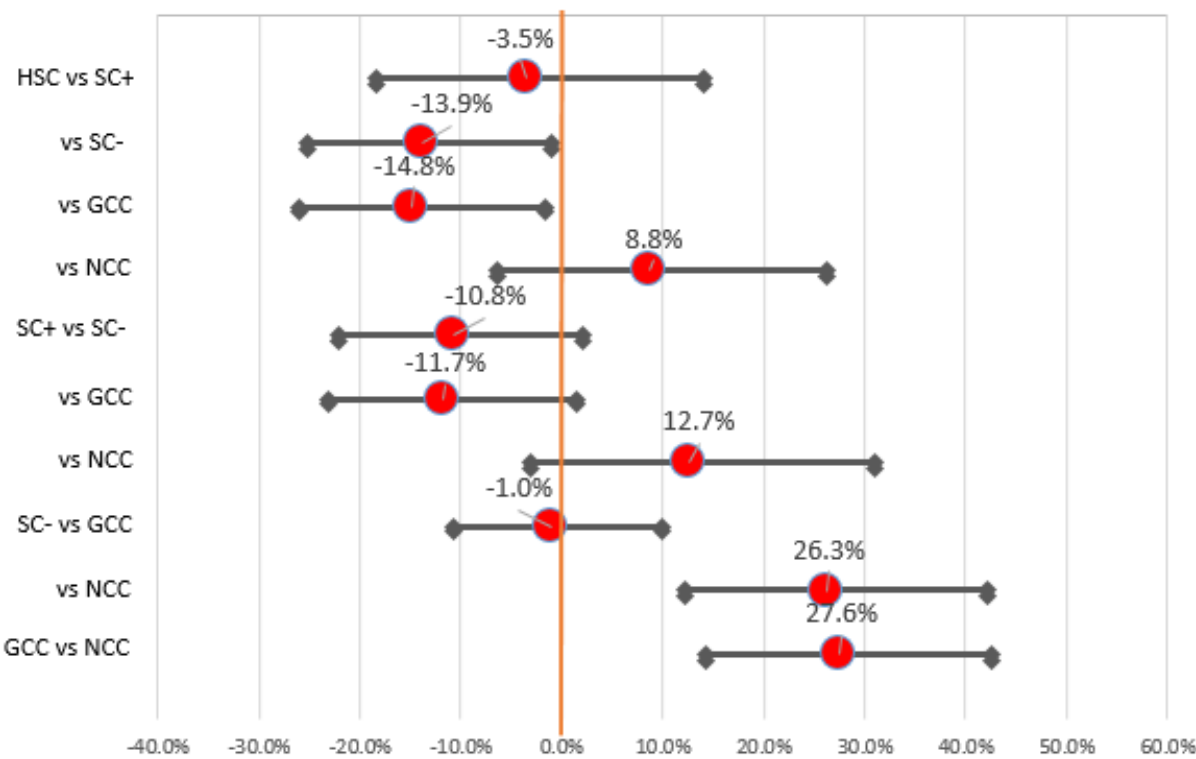

\begin{tabular}{rccccc}
\hline & & & & $95 \%$ & $95 \%$ \\
& $z$ Value & $\operatorname{Pr}>|z|$ & Difference & Low & High \\
\cline { 2 - 6 } HSC vs SC+ & 0.42 & 0.67 & $-3.5 \%$ & $-18.3 \%$ & $14.0 \%$ \\
vs SC- & 2.1 & 0.04 & $-13.9 \%$ & $-25.1 \%$ & $-1.0 \%$ \\
vs GCC & 2.2 & 0.03 & $-14.8 \%$ & $-26.1 \%$ & $-1.7 \%$ \\
vs NCC & 1.1 & 0.27 & $8.8 \%$ & $-6.3 \%$ & $26.3 \%$ \\
SC+ vs SC- & 1.66 & 0.10 & $-10.8 \%$ & $-22.0 \%$ & $2.1 \%$ \\
vs GCC & 1.74 & 0.08 & $-11.7 \%$ & $-23.2 \%$ & $1.6 \%$ \\
vs NCC & 1.56 & 0.12 & $12.7 \%$ & $-3.0 \%$ & $31.0 \%$ \\
SC- vs GCC & 0.19 & 0.85 & $-1.0 \%$ & $-10.8 \%$ & $9.9 \%$ \\
vs NCC & 3.88 & 0.00 & $26.3 \%$ & $12.3 \%$ & $42.2 \%$ \\
GCC vs NCC & 4.32 & $<.0001$ & $27.6 \%$ & $14.2 \%$ & $42.5 \%$ \\
\hline
\end{tabular}




\section{Pharmaceuticals costs difference}

Pharma costs difference - Moderate

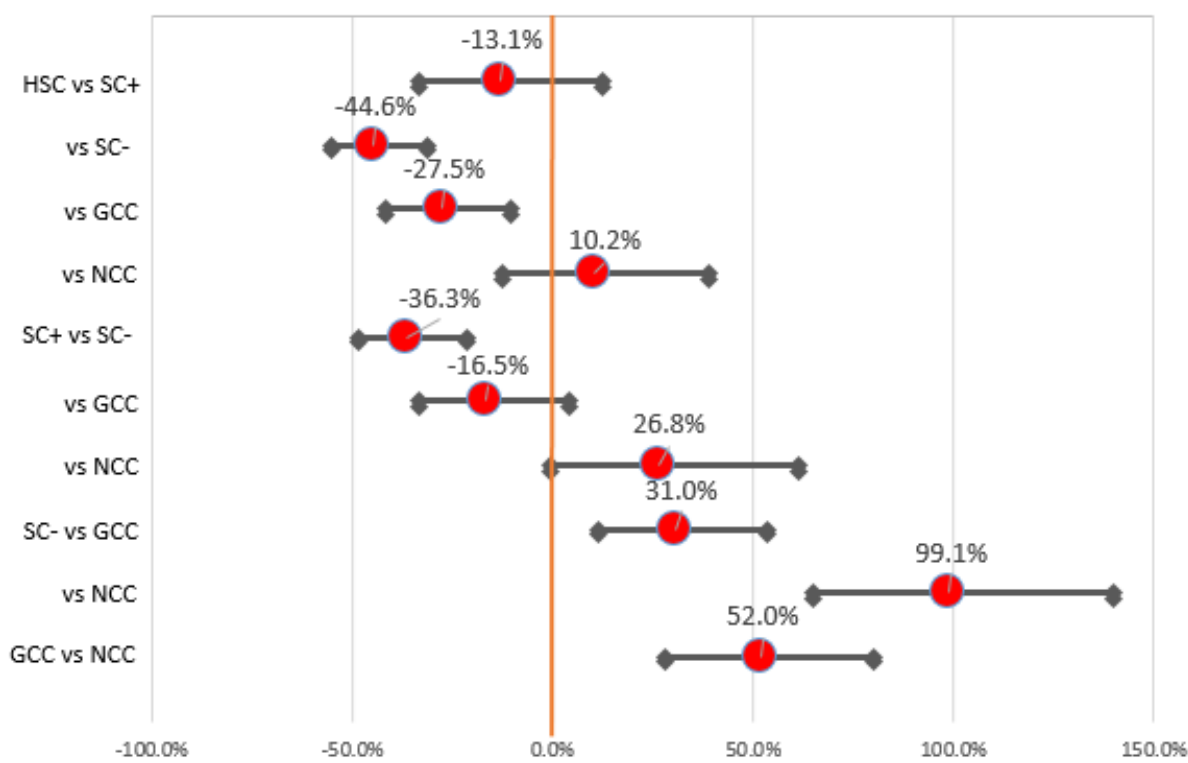

\begin{tabular}{rccccc}
\hline & & & & $95 \%$ & $95 \%$ \\
& $z$ Value & $\operatorname{Pr}>|z|$ & Difference & Low & High \\
\cline { 2 - 6 } HSC vs SC+ & 1.06 & 0.29 & $-13.1 \%$ & $-33.0 \%$ & $12.8 \%$ \\
vs SC- & 5.4 & $<.0001$ & $-44.6 \%$ & $-55.3 \%$ & $-31.4 \%$ \\
vs GCC & 2.96 & 0.00 & $-27.5 \%$ & $-41.4 \%$ & $-10.3 \%$ \\
vs NCC & 0.82 & 0.41 & $10.2 \%$ & $-12.6 \%$ & $39.0 \%$ \\
SC+ vs SC- & 4.19 & $<.0001$ & $-36.3 \%$ & $-48.4 \%$ & $-21.3 \%$ \\
vs GCC & 1.61 & 0.11 & $-16.5 \%$ & $-33.1 \%$ & $4.1 \%$ \\
vs NCC & 1.92 & 0.05 & $26.8 \%$ & $-0.5 \%$ & $61.6 \%$ \\
SC- vs GCC & -3.3 & 0.00 & $31.0 \%$ & $11.6 \%$ & $53.7 \%$ \\
vs NCC & 7.22 & $<.0001$ & $99.1 \%$ & $65.1 \%$ & $140.0 \%$ \\
GCC vs NCC & 4.81 & $<.0001$ & $52.0 \%$ & $28.2 \%$ & $80.3 \%$ \\
\hline
\end{tabular}




\section{Emergency department visits difference}

Emergency department visits difference - Moderate

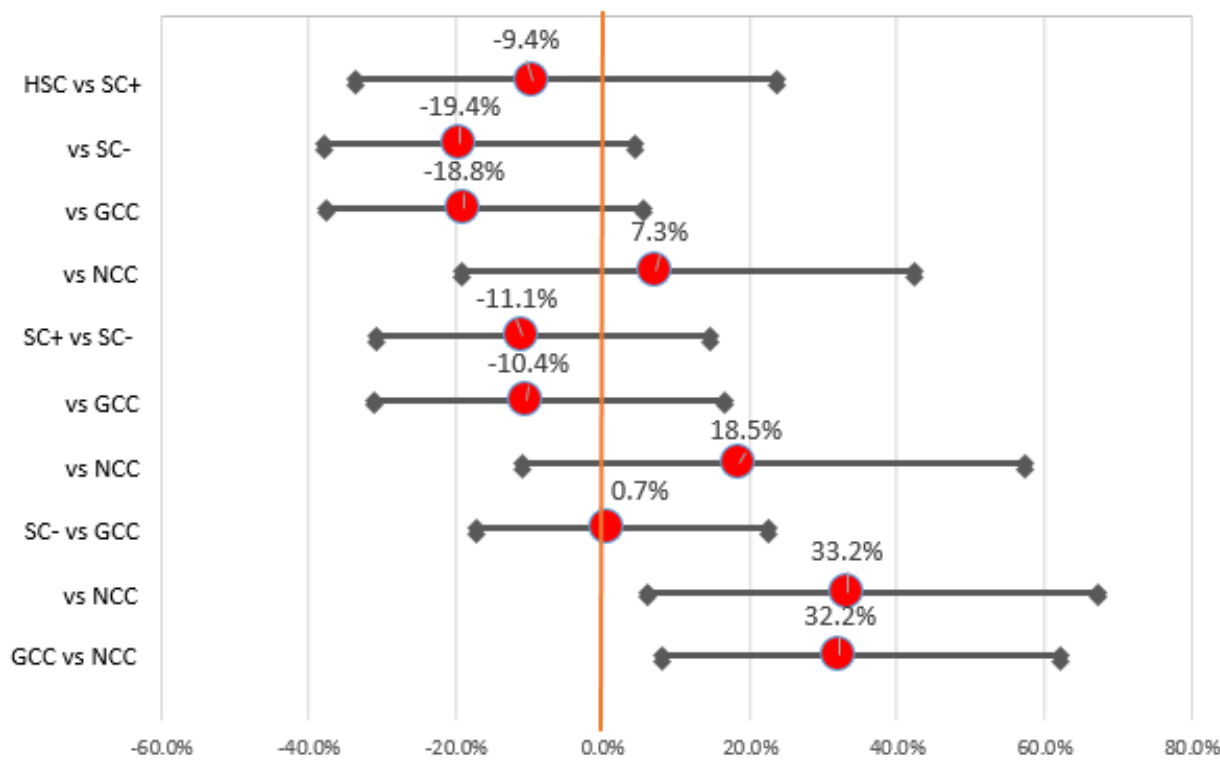

\begin{tabular}{rccccc}
\hline & & & & $95 \%$ & $95 \%$ \\
& z Value & $\operatorname{Pr}>|z|$ & Difference & Low & High \\
\cline { 2 - 6 } HSC vs SC+ & 0.62 & 0.54 & $-9.4 \%$ & $-33.6 \%$ & $23.7 \%$ \\
vs SC- & 1.64 & 0.10 & $-19.4 \%$ & $-37.7 \%$ & $4.3 \%$ \\
vs GCC & 1.57 & 0.12 & $-18.8 \%$ & $-37.5 \%$ & $5.4 \%$ \\
vs NCC & 0.49 & 0.62 & $7.3 \%$ & $-19.1 \%$ & $42.4 \%$ \\
SC+ vs SC- & 0.91 & 0.36 & $-11.1 \%$ & $-30.9 \%$ & $14.5 \%$ \\
vs GCC & 0.82 & 0.41 & $-10.4 \%$ & $-31.2 \%$ & $16.6 \%$ \\
vs NCC & 1.17 & 0.24 & $18.5 \%$ & $-10.9 \%$ & $57.5 \%$ \\
SC- vs GCC & -0.07 & 0.94 & $0.7 \%$ & $-17.3 \%$ & $22.6 \%$ \\
vs NCC & 2.47 & 0.01 & $33.2 \%$ & $6.1 \%$ & $67.2 \%$ \\
GCC vs NCC & 2.7 & 0.01 & $32.2 \%$ & $7.9 \%$ & $62.0 \%$ \\
\hline
\end{tabular}




\section{Hospitalizations difference}

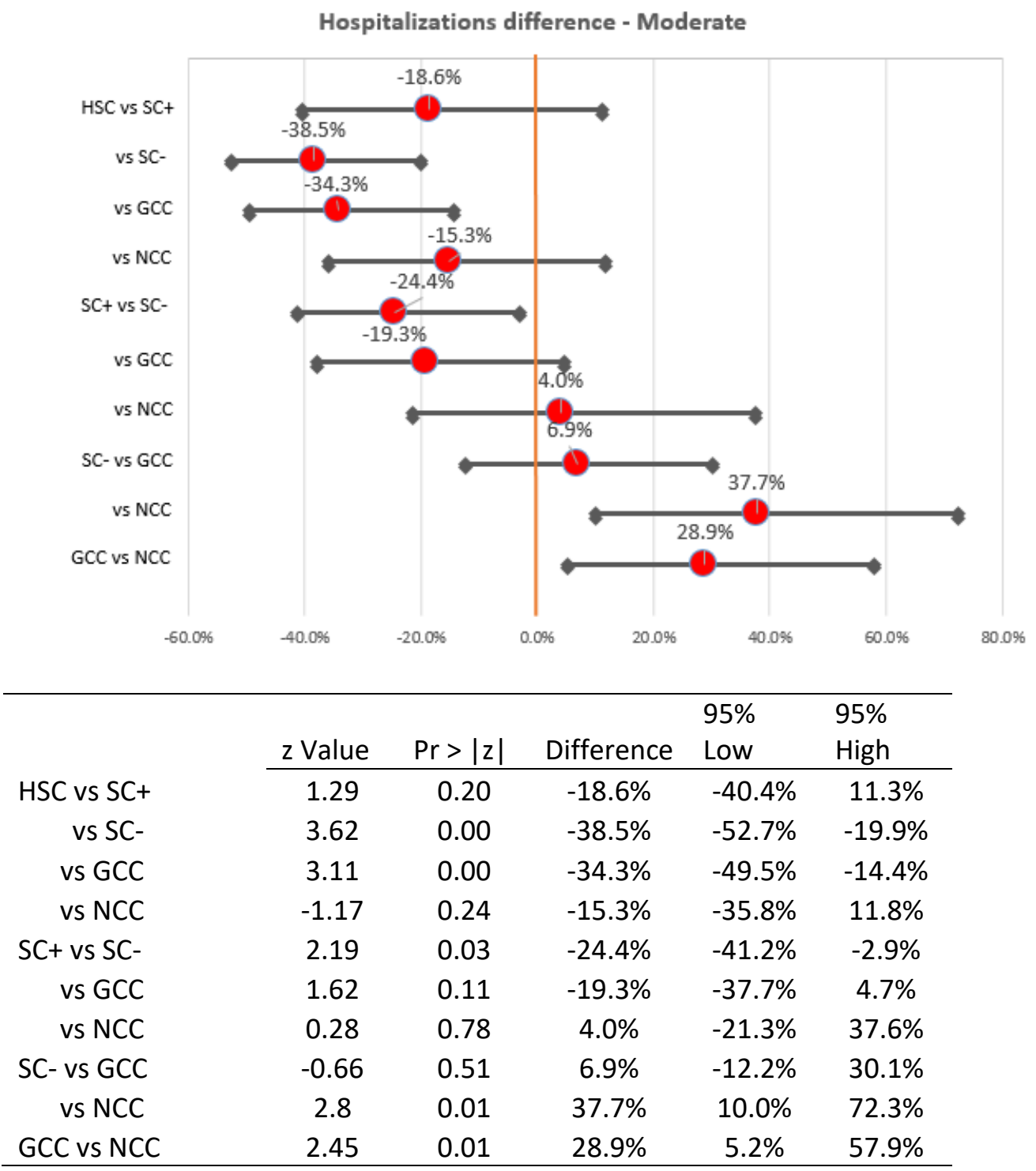

\section{Adult patients with severe lesions}

It appeared to be feasible to delete all imbalance by adding quadratics and interactions. The final Ordinal Logit Model with 12 main effects, two quadratic effect (i.e. number of interventions, primary diagnostic code) and five interaction effects (i.e. number of interventions*age category, number of interventions*primary diagnostic code, number of interventions*chronical ill, number of interventions*increased reimbursement, age category*chronical ill) resulted in total balance in all 12 covariates. However, because the relatively small sample size, we added all covariates to the final regression model to obtain an even more robust estimation of the impact of care level on the respective outcomes.

Table 5 shows how the excluded patients ( $\mathrm{N}=107,32.8 \%$ ) differed from the included patients $(\mathrm{N}=219,67.2 \%)$. The obtained results does not apply on (i) a small group of patients who could be characterized by having had less interventions, had a lower income, older age, a different marital status, and who were relatively more diagnosed primarily with hypoplastic left heart syndrome or transposition of the great arteries, and relatively less with univentricular heart 
or congenitally corrected transposition of the great arteries. These patients experienced a lower care level on average. And (ii) a small group of patients who could be characterized by having had more available informal caregivers, being more self-employed, having a syndrome, being younger, and who were relatively more diagnosed primarily with a hypoplastic left heart syndrome, a pulmonary atresia with ventricular septal defect, or a truncus arteriosus. These patients experienced a higher care level on average.

Table 5. Covariates, care level, and outcomes of included and excluded patients with moderate lesions.

\begin{tabular}{|c|c|c|c|c|}
\hline & & $\begin{array}{l}\text { Excluded low } \\
\qquad(\mathrm{N}=65)\end{array}$ & $\begin{array}{l}\text { Included } \\
(\mathrm{N}=219)\end{array}$ & $\begin{array}{l}\text { Excluded High } \\
\qquad(\mathrm{N}=42)\end{array}$ \\
\hline & & Mean/\% & Mean/\% & Mean/\% \\
\hline \multicolumn{2}{|l|}{$\begin{array}{l}V \text { (number of available informal } \\
\text { caregivers) }\end{array}$} & 0.36 & 0.45 & $0.77^{*}$ \\
\hline \multicolumn{2}{|l|}{$\sqrt{ }($ number of interventions) } & $0.67^{*}$ & 1.49 & 1.64 \\
\hline \multicolumn{2}{|l|}{ Self-employment } & $11 \%$ & $6 \%$ & $31 \% *$ \\
\hline \multicolumn{2}{|l|}{ Increased reimbursement } & $25 \%$ & $24 \%$ & $21 \%$ \\
\hline \multicolumn{2}{|l|}{ Chronical ill } & $18 \%$ & $22 \%$ & $19 \%$ \\
\hline \multicolumn{2}{|l|}{ Syndrome } & $2 \%$ & $2 \%$ & $12 \% *$ \\
\hline \multicolumn{2}{|l|}{ Income rank (quartiles) } & $1.15^{*}$ & 1.55 & 1.14 \\
\hline \multicolumn{2}{|l|}{ Age category } & $2.25^{*}$ & 1.39 & $1.14 *$ \\
\hline \multicolumn{2}{|l|}{ Sex (men) } & $60 \%$ & $58 \%$ & $52 \%$ \\
\hline \multirow[t]{4}{*}{ Marital status } & Unmarried & $48 \% *$ & $79 \%$ & $86 \%$ \\
\hline & Married & $40 \% *$ & $21 \%$ & $14 \%$ \\
\hline & Widow(er) & $2 \%$ & $0 \%$ & $0 \%$ \\
\hline & Divorced & $11 \% *$ & $0 \%$ & $0 \%$ \\
\hline \multirow[t]{6}{*}{ Household type } & Single, children & $14 \%$ & $6 \%$ & $2 \%$ \\
\hline & Single, no children & $11 \%$ & $14 \%$ & $7 \%$ \\
\hline & Partner, children & $20 \%$ & $11 \%$ & $10 \%$ \\
\hline & Partner, no children & $54 \%$ & $68 \%$ & $81 \%$ \\
\hline & Collective household & $0 \%$ & $0 \%$ & $0 \%$ \\
\hline & Other & $2 \%$ & $1 \%$ & $0 \%$ \\
\hline \multirow[t]{11}{*}{ Primary diagnostic code } & HLHS & $8 \% *$ & $0 \%$ & $5 \% *$ \\
\hline & $\begin{array}{l}\text { Univentricular } \\
\text { physiology }\end{array}$ & $5 \% *$ & $22 \%$ & $19 \%$ \\
\hline & Tricuspid atresia & $0 \%$ & $2 \%$ & $5 \%$ \\
\hline & TOF & $11 \% *$ & $3 \%$ & $0 \%$ \\
\hline & PA with VSD & $0 \%$ & $0 \%$ & $19 \% *$ \\
\hline & PA without VSD & $2 \%$ & $2 \%$ & $5 \%$ \\
\hline & DORV & $17 \%$ & $11 \%$ & $0 \%$ \\
\hline & DILV & $0 \%$ & $0 \%$ & $0 \%$ \\
\hline & TA & $5 \%$ & $2 \%$ & $10 \% *$ \\
\hline & TGA & $11 \% *$ & $49 \%$ & $38 \%$ \\
\hline & TGA-CC & $43 \% *$ & $9 \%$ & $0 \%$ \\
\hline \multicolumn{2}{|l|}{ Care level } & $1.09 *$ & 2.21 & $3.02 *$ \\
\hline \multicolumn{5}{|l|}{ Emergency department visits } \\
\hline \multicolumn{2}{|l|}{ (per PY) } & 0.60 & 0.36 & 0.26 \\
\hline \multicolumn{2}{|l|}{ Hospitalizations (per PY) } & 0.58 & 0.48 & 0.41 \\
\hline \multicolumn{2}{|l|}{ Hospitalization cost (per PY) } & $5147 €$ & $4056 €$ & $3199 €$ \\
\hline \multicolumn{2}{|l|}{ Pharmaceutical costs (per PY) } & $1223 €$ & $1777 €$ & $514 €$ \\
\hline \multicolumn{2}{|l|}{ Outpatient costs (per PY) } & $2992 €$ & $2087 €$ & $1646 €$ \\
\hline \multicolumn{2}{|l|}{ Total medical costs (per PY) } & $9362 €$ & $7920 €$ & $5359 €$ \\
\hline
\end{tabular}


*=significantly different from the included group. DIRV: double inlet left ventricle; DORV: double outlet right ventricle; HLHS: hypoplastic left heart syndrome; PA: pulmonary atresia; PY; patient year; TA: truncus arteriosus; TGA: transposition of the great arteries; TGA-cc: congenitally corrected transposition of the great arteries. Care level: from 0 (general care) to 4 (highly specialized care) Income rank: 0 (lowest quartile) to 3 (highest quartile). Age category: 1=18-29 years old, 2=30-39 years old, $3=40+$ years old.

\section{Total costs difference}

Total costs difference - Severe

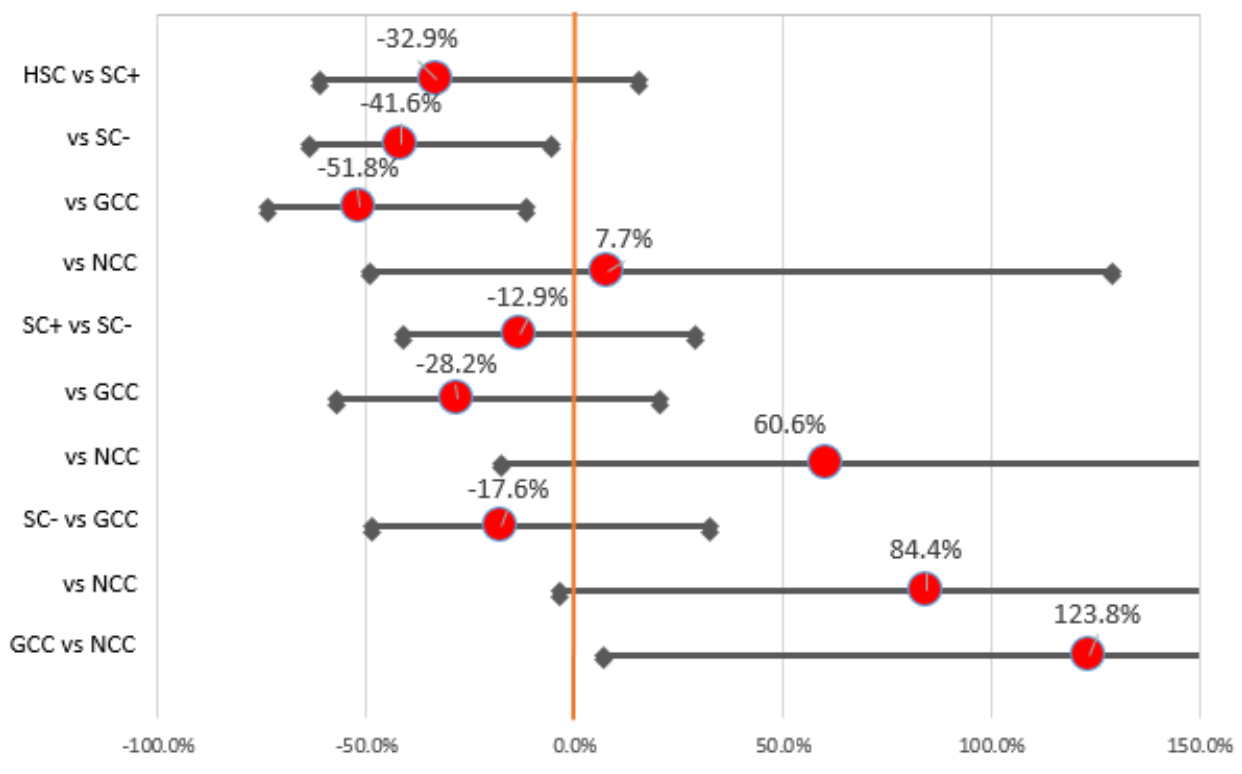

\begin{tabular}{cccccc}
\hline & & & & $95 \%$ & $95 \%$ \\
HSC vs SC+ & 1.44 & 0.15 & $-32.9 \%$ & $-61.0 \%$ & $15.4 \%$ \\
vs SC- & 2.19 & 0.03 & $-41.6 \%$ & $-63.9 \%$ & $-5.6 \%$ \\
vs GCC & 2.35 & 0.02 & $-51.8 \%$ & $-73.8 \%$ & $-11.4 \%$ \\
vs NCC & 0.19 & 0.85 & $7.7 \%$ & $-49.3 \%$ & $129.1 \%$ \\
SC+ vs SC- & 0.69 & 0.49 & $-12.9 \%$ & $-41.1 \%$ & $28.7 \%$ \\
vs GCC & 1.26 & 0.21 & $-28.2 \%$ & $-57.2 \%$ & $20.4 \%$ \\
vs NCC & 1.39 & 0.17 & $60.6 \%$ & $-17.8 \%$ & $214.0 \%$ \\
SC- vs GCC & 0.8 & 0.42 & $-17.6 \%$ & $-48.6 \%$ & $32.2 \%$ \\
vs NCC & 1.84 & 0.07 & $84.4 \%$ & $-3.8 \%$ & $253.5 \%$ \\
GCC vs NCC & 2.14 & 0.03 & $123.8 \%$ & $7.0 \%$ & $367.8 \%$ \\
\hline
\end{tabular}


Hospitalization costs difference

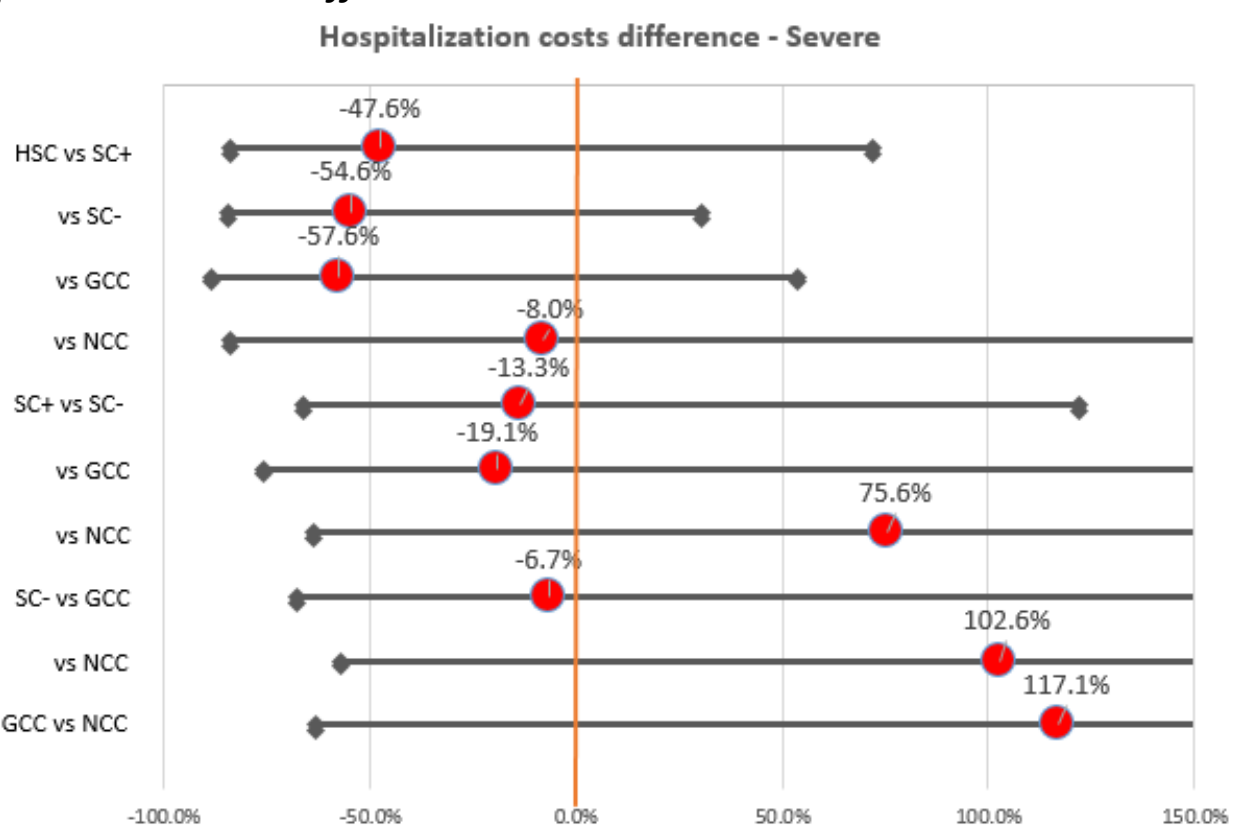

\begin{tabular}{rccccc}
\hline & & & & $95 \%$ & $95 \%$ \\
& $z$ Value & $\operatorname{Pr}>|z|$ & Difference & Low & High \\
\cline { 2 - 6 } HSC vs SC+ & 1.07 & 0.29 & $-47.6 \%$ & $-84.1 \%$ & $72.1 \%$ \\
vs SC- & 1.46 & 0.14 & $-54.6 \%$ & $-84.2 \%$ & $30.7 \%$ \\
vs GCC & 1.31 & 0.19 & $-57.6 \%$ & $-88.3 \%$ & $53.6 \%$ \\
vs NCC & -0.09 & 0.93 & $-8.0 \%$ & $-84.1 \%$ & $433.2 \%$ \\
SC+ vs SC- & 0.3 & 0.77 & $-13.3 \%$ & $-66.2 \%$ & $122.1 \%$ \\
vs GCC & 0.34 & 0.73 & $-19.1 \%$ & $-75.8 \%$ & $170.2 \%$ \\
vs NCC & 0.7 & 0.48 & $75.6 \%$ & $-63.4 \%$ & $742.8 \%$ \\
SC- vs GCC & 0.13 & 0.90 & $-6.7 \%$ & $-67.8 \%$ & $170.7 \%$ \\
vs NCC & 0.89 & 0.37 & $102.6 \%$ & $-57.3 \%$ & $861.5 \%$ \\
GCC vs NCC & 0.86 & 0.39 & $117.1 \%$ & $-63.0 \%$ & $1172.4 \%$ \\
\hline
\end{tabular}




\section{Outpatient costs difference}

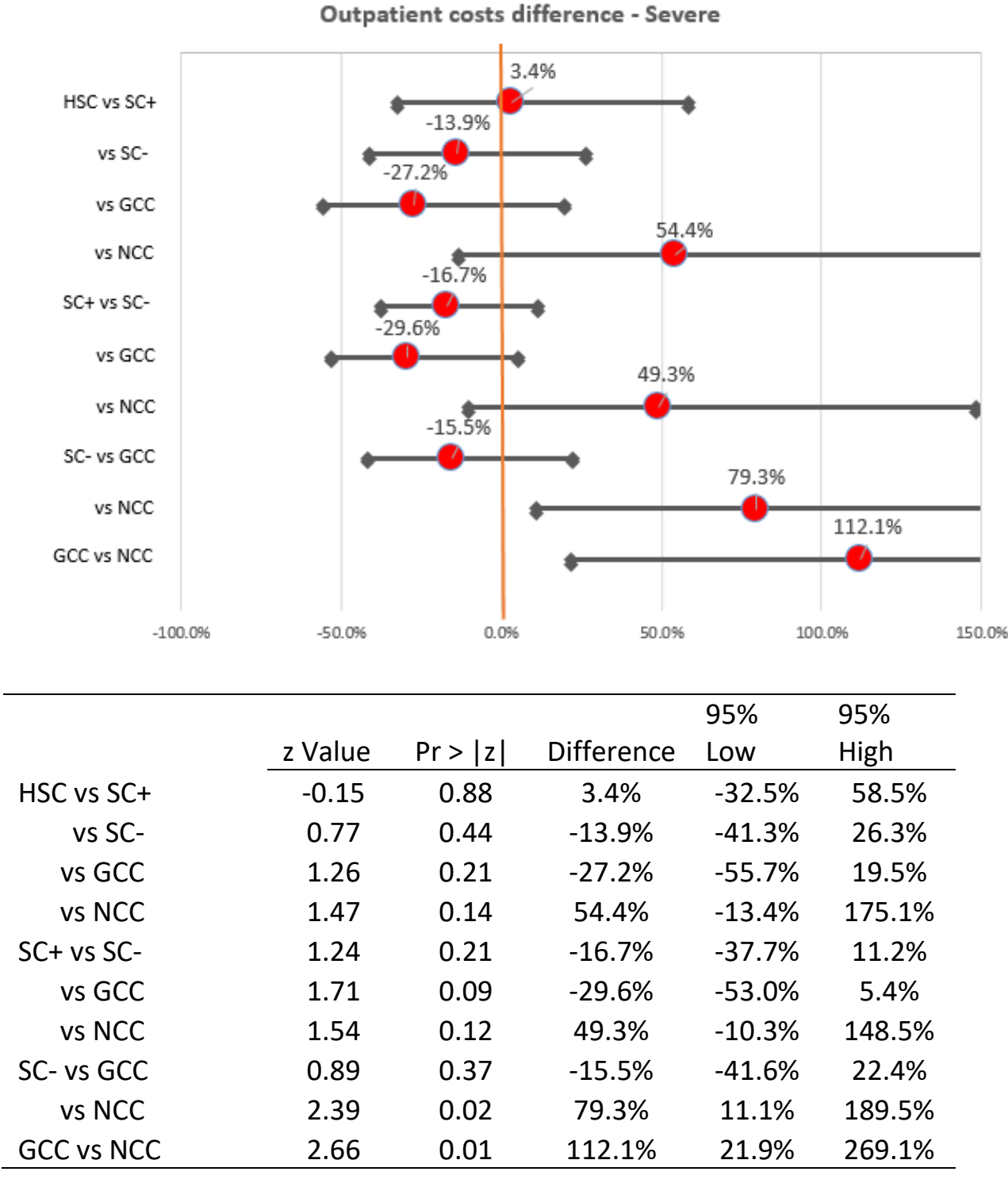




\section{Pharmaceuticals costs difference}

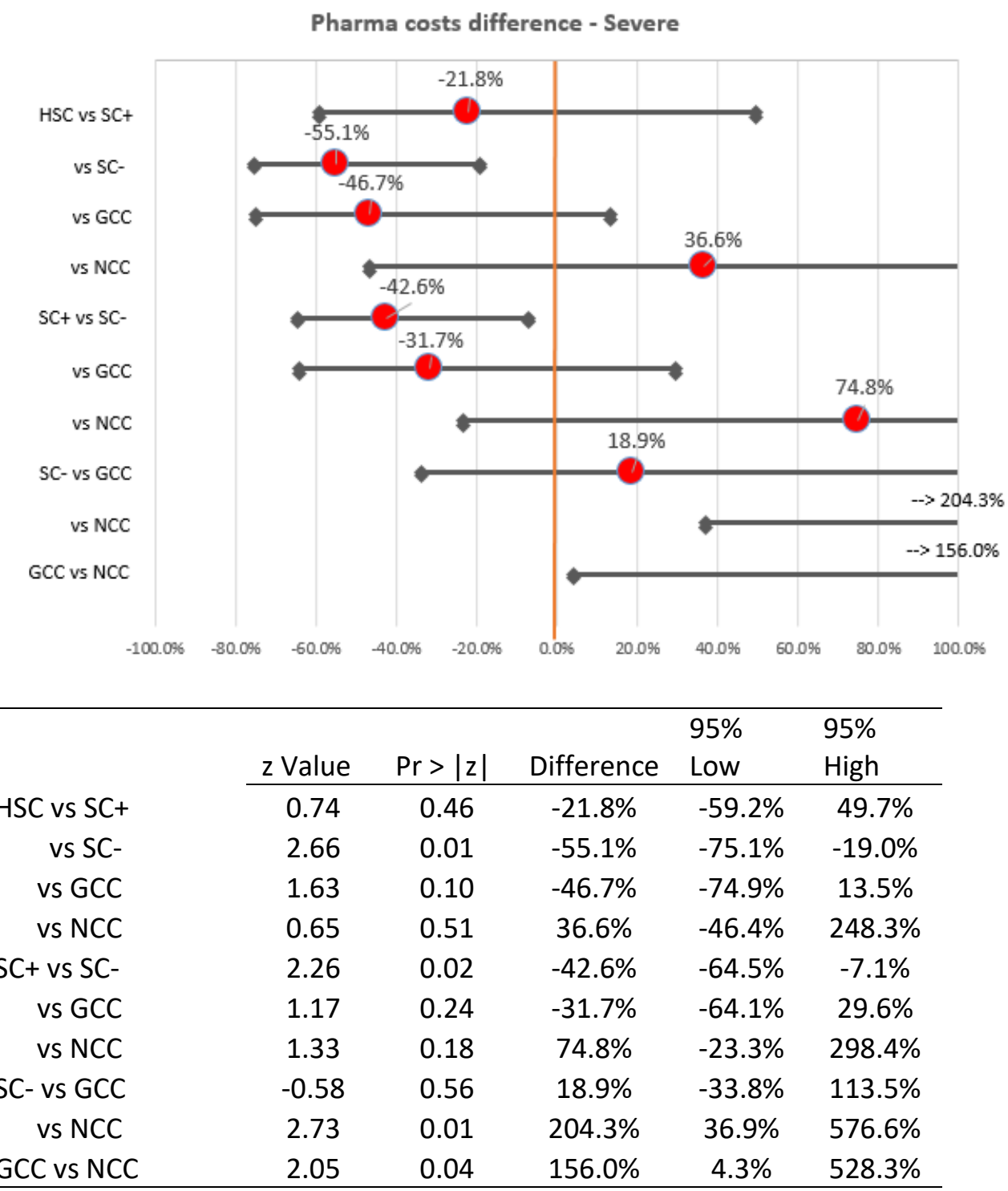


Emergency department visits difference

Emergency department visits difference - Severe

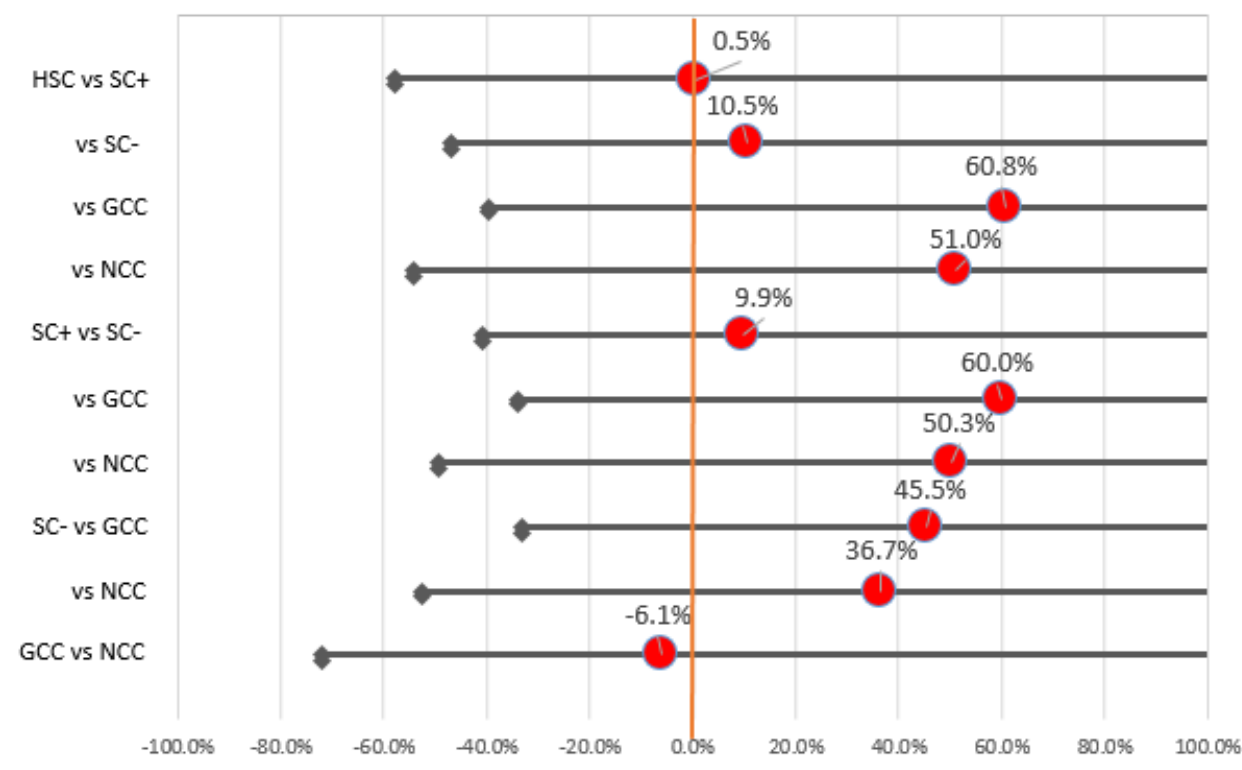

\begin{tabular}{rrrcrl}
\hline & & & & $95 \%$ & $95 \%$ \\
& $z$ Value & $\operatorname{Pr}>|z|$ & Difference & Low & High \\
\cline { 2 - 6 } HSC vs SC+ & -0.01 & 0.99 & $0.5 \%$ & $-57.9 \%$ & $139.8 \%$ \\
vs SC- & -0.27 & 0.79 & $10.5 \%$ & $-47.0 \%$ & $130.5 \%$ \\
vs GCC & -0.95 & 0.34 & $60.8 \%$ & $-39.6 \%$ & $328.4 \%$ \\
vs NCC & 0.68 & 0.50 & $51.0 \%$ & $-54.1 \%$ & $396.9 \%$ \\
SC+ vs SC- & -0.3 & 0.77 & $9.9 \%$ & $-41.0 \%$ & $104.8 \%$ \\
vs GCC & -1.04 & 0.30 & $60.0 \%$ & $-34.1 \%$ & $288.7 \%$ \\
vs NCC & 0.73 & 0.46 & $50.3 \%$ & $-49.4 \%$ & $346.0 \%$ \\
SC- vs GCC & -0.95 & 0.34 & $45.5 \%$ & $-33.1 \%$ & $216.8 \%$ \\
vs NCC & 0.58 & 0.56 & $36.7 \%$ & $-52.7 \%$ & $295.4 \%$ \\
GCC vs NCC & -0.1 & 0.92 & $-6.1 \%$ & $-71.8 \%$ & $213.1 \%$ \\
\hline
\end{tabular}




\section{Hospitalizations difference}

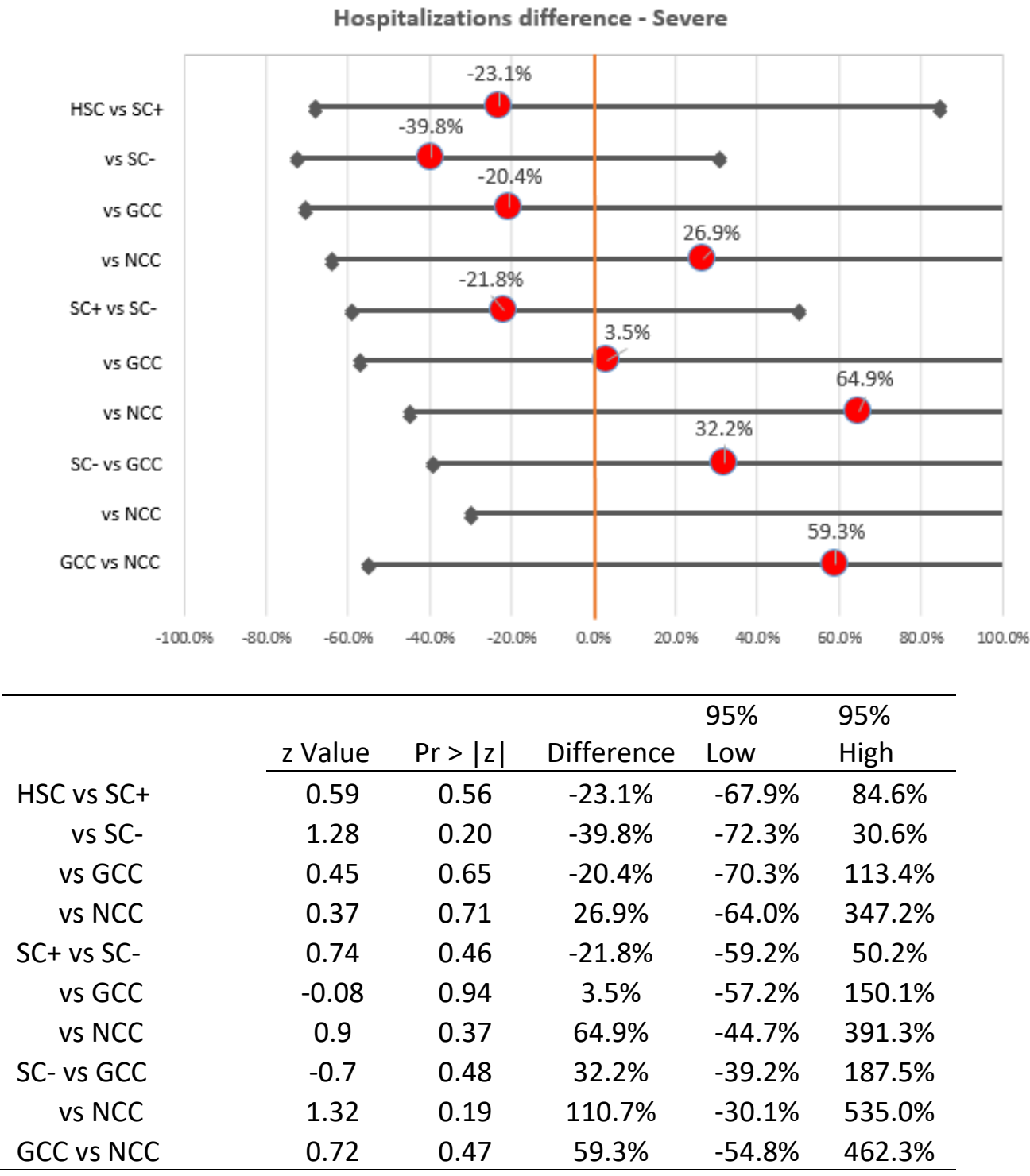

\section{References}

1. Zanutto E, Lu B, Hornik R. Using Propensity Score Subclassification for Multiple Treatment Doses to Evaluate a National Antidrug Media Campaign. Journal of Educational and Behavioral Statistics 2005;30(1):15.

2. Cochran W. The effectiveness of adjustment by subclassification in removing bias in observational studies. Biometrics 1968;24:9.

3. Rosenbaum PR, Rubin DB. Reducing bias in observational studies using subclassification on the propensity score. Journal of the American Statistical Association 1984;79:9.

4. Tsiatis AA, Davidian $M$, Zhang $M$, et al. Covariate adjustment for two-sample treatment comparisons in randomized clinical trials: a principled yet flexible approach. Stat Med 2008;27(23):4658-77. doi: 10.1002/sim.3113 


\section{Supplement S2. Sensitivity analysis: exclusion of patients who died during the study period}

of the paper

Different Levels of Care for Follow-up of Adults with Congenital Heart Disease; Impact on Medical Costs, Hospitalizations, and Emergency

\section{Department Visits}

Running title: Different Care Levels for ACHD Follow-up 


\begin{tabular}{|c|c|c|c|c|}
\hline & & $\begin{array}{l}\text { Excluded low } \\
\qquad(N=59)\end{array}$ & $\begin{array}{l}\text { Included } \\
(\mathrm{N}=3559)\end{array}$ & $\begin{array}{l}\text { Excluded High } \\
\qquad(\mathrm{N}=25)\end{array}$ \\
\hline & & Mean/\% & Mean/\% & Mean/\% \\
\hline \multicolumn{2}{|l|}{$\begin{array}{l}\mathrm{V} \text { (number of available informal } \\
\text { caregivers) }\end{array}$} & 0.28 & 0.40 & 0.43 \\
\hline \multicolumn{2}{|l|}{$\checkmark($ number of interventions) } & $0.15^{*}$ & 0.35 & $1.54^{*}$ \\
\hline \multicolumn{2}{|l|}{ Self-employment } & $8 \%$ & $9 \%$ & $8 \%$ \\
\hline \multicolumn{2}{|l|}{ Increased reimbursement } & $8 \%$ & $9 \%$ & $24 \% *$ \\
\hline \multicolumn{2}{|l|}{ Chronical sick } & $3 \%$ & $7 \%$ & $28 \% *$ \\
\hline \multicolumn{2}{|l|}{ Syndrome } & $0 \%$ & $3 \%$ & $16 \% *$ \\
\hline \multicolumn{2}{|l|}{ Income rank (quartiles) } & $0.63^{*}$ & 1.59 & 1.40 \\
\hline \multicolumn{2}{|l|}{ Age category } & 1.85 & 2.08 & $1.60 *$ \\
\hline \multicolumn{2}{|l|}{ Gender (male) } & $44 \%$ & $43 \%$ & $60 \%$ \\
\hline \multirow[t]{4}{*}{ Marital status } & Unmarried & $64 \% *$ & $45 \%$ & $76 \% *$ \\
\hline & Married & $10 \% *$ & $47 \%$ & $20 \% *$ \\
\hline & Widow(er) & $8 \% *$ & $2 \%$ & $0 \%$ \\
\hline & Divorced & $17 \% *$ & $6 \%$ & $4 \%$ \\
\hline \multirow[t]{6}{*}{ Household type } & Single, children & $22 \% *$ & $8 \%$ & $16 \%$ \\
\hline & Single, no children & $37 \% *$ & $8 \%$ & $0 \%$ \\
\hline & Partner, children & $2 \% *$ & $21 \%$ & $16 \%$ \\
\hline & Partner, no children & $25 \% *$ & $62 \%$ & $56 \%$ \\
\hline & Collective household & $2 \% *$ & $0 \%$ & $8 \% *$ \\
\hline & Other & $12 \% *$ & $1 \%$ & $4 \%$ \\
\hline \multirow[t]{5}{*}{ Primary diagnostic code } & AV abnormality & $0 \% *$ & $11 \%$ & $88 \% *$ \\
\hline & ASD 2 & $15 \%$ & $26 \%$ & $4 \% *$ \\
\hline & VSD & $83 \% *$ & $29 \%$ & $0 \% *$ \\
\hline & MV abnormality & $0 \%$ & $8 \%$ & $4 \%$ \\
\hline & Other & $2 \% *$ & $26 \%$ & $4 \% *$ \\
\hline \multicolumn{2}{|l|}{ Care level } & $0.44 *$ & 0.91 & $2.08^{*}$ \\
\hline \multicolumn{5}{|l|}{ Emergency department visits } \\
\hline \multicolumn{2}{|l|}{ Hospitalizations (per PY) } & 0.22 & 0.26 & 0.28 \\
\hline \multicolumn{2}{|l|}{ Hospitalization cost (per PY) } & $1087 €$ & $1697 €$ & $1631 €$ \\
\hline \multicolumn{2}{|l|}{ Pharmaceutical costs (per PY) } & $353 €$ & $715 €$ & $978 €$ \\
\hline \multicolumn{2}{|l|}{ Outpatient costs (per PY) } & $1374 €^{*}$ & $1593 €$ & $1597 €$ \\
\hline \multicolumn{2}{|l|}{ Total medical costs (per PY) } & $2814 €^{*}$ & $4006 €$ & $4207 €$ \\
\hline
\end{tabular}

ASD 1: atrial septal defect type 1; ASD 2: atrial septal defect 2; AV: aortic valve; AVSD: atrioventricular septal defect; CoA: coarctation of the aorta; LVOT left ventricular outflow track; MV: mitral valve; PV: pulmonary valve; TOF: tetralogy of Fallot; VSD: ventricular septal defect 


\section{Total costs difference}

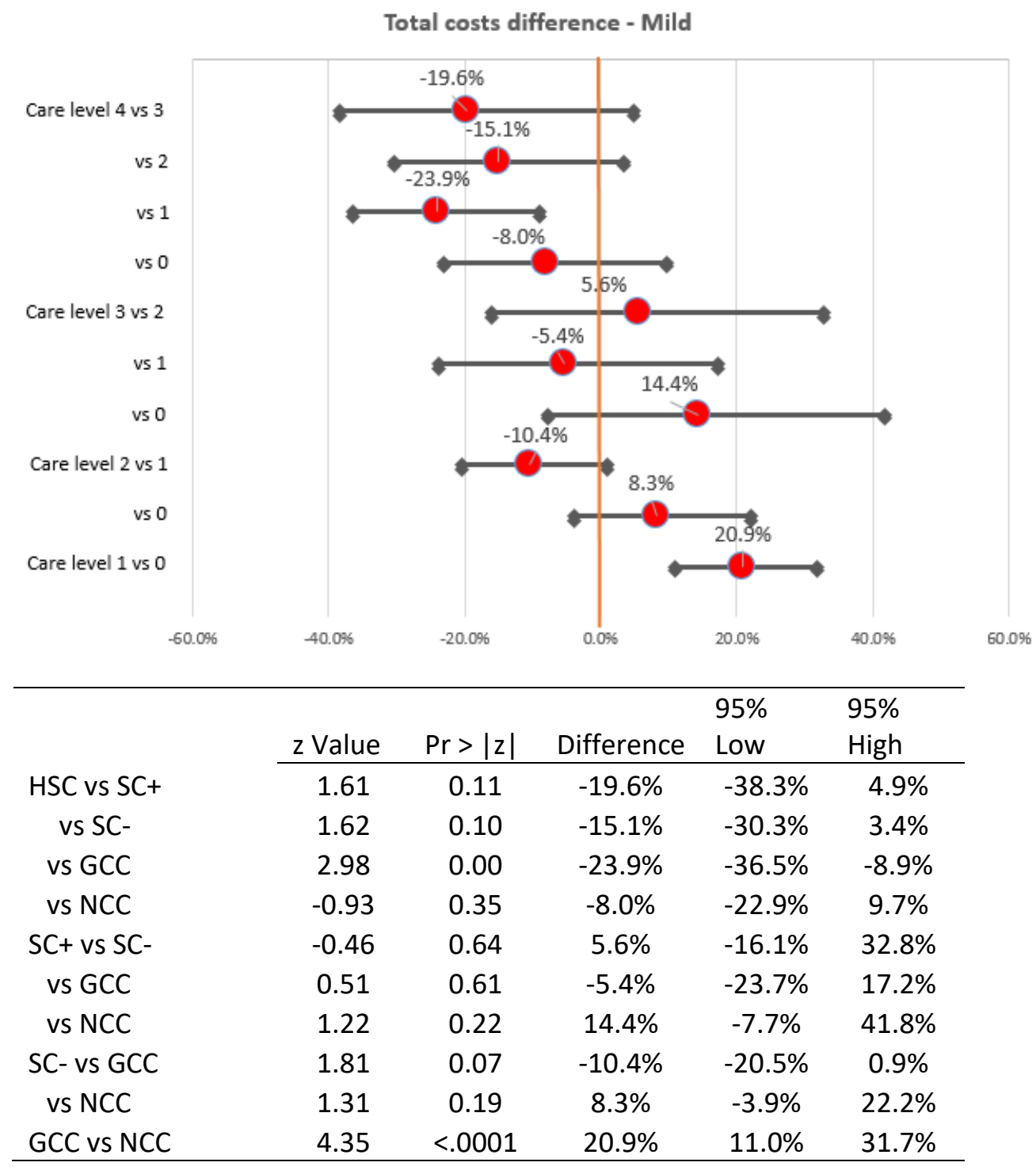

